\title{
Wagner Castropil
}

\section{Valor diagnóstico e prognóstico dos métodos de imagem na fratura de estresse da tíbia: correlação clínico-radiológica}

Tese apresentada à Faculdade de Medicina da Universidade de São Paulo para obtenção do título de Doutor em Ciências

Área de concentração: Radiologia

Orientador: Prof. Dr. Carlos Buchpiguel

São Paulo

2006 


\section{Wagner Castropil}

\section{Valor diagnóstico e prognóstico dos métodos de imagem na fratura de estresse da tíbia: correlação clínico-radiológica}

Tese apresentada à Faculdade de Medicina da Universidade de São Paulo para obtenção do título de Doutor em Ciências

Área de concentração: Radiologia

Orientador: Prof. Dr. Carlos Buchpiguel

São Paulo

2006 
A motivação de realizar este estudo foi de amenizar 0 tempo de sofrimento dos atletas, aos quais estou ligado pessoal e profissionalmente.

D edico este trabalho à Christiana, minha esposa, por seu companheirismo, dedicação e capacidade de evolução. $M$ inhas conquistas são frutos de nosso amor. 


\section{AGRADECIMENTOS ESPECIAIS}

Ao Prof. Dr. Carlos Buchpiguel, pela oportunidade, postura e ensinamentos como orientador neste estudo.

Ao Pedro Fukui, pelo grande auxílio e competência na realização da análise estatística.

Aos colegas Dr. Carlos Longo, Dr. Hamilton Guidorizzi e Dra. Amisa Guimarães, pela paciência na realização dos exames e discussão dos resultados.

A meus amigos do Instituto Vita, que acreditaram no meu sonho, engrandeceram-no, transformando-o em nosso sonho.

Ao Dr. José Luiz Pistelli, pelo carinho, amor e por me ensinar o verdadeiro sentido da profissão que escolhi. 


\section{NORMALIZAÇÃO ADOTADA}

Esta tese está de acordo com:

Terminologia Anatômica em Português, conforme a TERMINOLOGIA ANATÔMICA INTERNACIONAL DA FEDERATIVE COMMITTEE ON ANATOMICAL TERMINOLOGY - FCAT (COMISSÃO FEDERATIVA DE TERMINOLOGIA ANATÔMICA - CFTA), aprovada em 1998 e traduzida pela Comissão de Terminologia Anatômica da Sociedade Brasileira de Anatomia - CTA-SBA. 1. Ed. (Brasileira) São Paulo, Editora Manole Ltda. 2001. 248p.

Universidade de São Paulo. Faculdade de Medicina. Serviço de Biblioteca e Documentação. GUIA DE APRESENTAÇÃO DE DISSERTAÇÕES, TESES E MONOGRAFIAS. Elaborado por Anneliese Carneiro da Cunha, Maria Júlia de A. L. Freddi, Maria F. Crestana, Marinalva de Souza Aragão, Suely Campos Cardoso, Valéria Vilhena. São Paulo: Serviço de Biblioteca e Documentação; 2004.

Utilizaram-se a terminologia e as definições estatísticas conforme o GUIA PARA EXPRESSÃO DA INCERTEZA DE MEDIÇÃO, Segunda Edição Brasileira do Guide to the Expression of Uncertainty in Measurement (BIPM, IEC, IFCC, ISSO, IUPAC, IUPAP, OIML, 1983). Edição Revisada (agosto de 1998) - Rio de Janeiro: ABNT, INMETRO, SBM, 1998. 
As abreviaturas dos títulos dos periódicos estão de acordo com LIST OF JOURNALS INDEXED IN INDEX MEDICUS (1992) e na LILACS LITERATURA LATINO-AMERICANA E DO CARIBE EM CIÊNCIAS DA SAÚDE (1995).

Referências: adaptado de International Committee of Medical Journals Editors (Vancouver). 


\section{SUMÁRIO}

\section{RESUMO}

\section{SUMMARY}

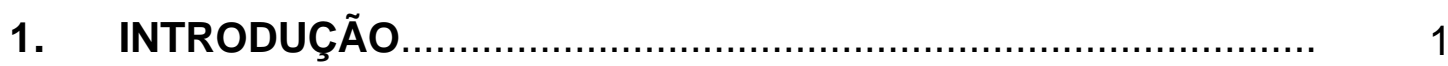

2. OBJETIVO

3. REVISÃO DA LITERATURA .......................................................

3.1 Aspectos clínicos............................................................

3.2 Aspectos radiológicos...................................................... 21

4. MÉTODOS ...................................................................... 30

4.1 Casuística............................................................. 31

4.2 Metodologia................................................................. 35

4.3 Análise estatística.......................................................... 43

5. RESULTADOS ....................................................................... 46

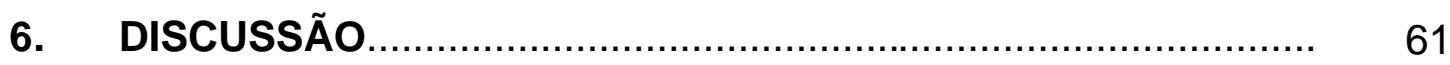

7. CONCLUSÕES........................................................................ 81

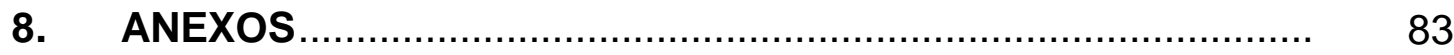

9. REFERÊNCIAS .................................................................. 88 


\section{SUMÁRIO}

\section{RESUMO}

\section{SUMMARY}

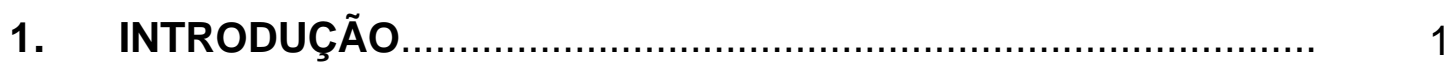

2. OBJETIVO

3. REVISÃO DA LITERATURA .......................................................

3.1 Aspectos clínicos............................................................

3.2 Aspectos radiológicos...................................................... 21

4. MÉTODOS ...................................................................... 30

4.1 Casuística............................................................. 31

4.2 Metodologia................................................................. 35

4.3 Análise estatística.......................................................... 43

5. RESULTADOS ....................................................................... 46

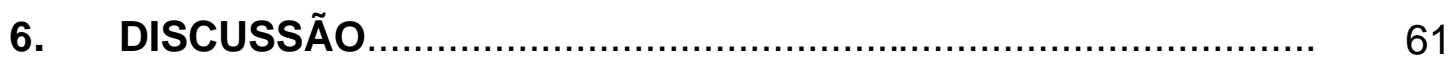

7. CONCLUSÕES........................................................................ 81

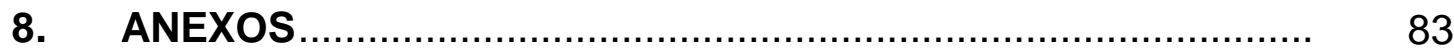

9. REFERÊNCIAS .................................................................. 88 


\section{RESUMO}

\section{Castropil, W - Valor diagnóstico e prognóstico dos métodos de imagem} na fratura de estresse da tíbia: correlação clínico-radiológica. (Doutorado). São Paulo. Faculdade de Medicina, Universidade de São Paulo; 2006.

Um grande problema em atletas com fraturas por estresse é o tempo necessário para sua recuperação completa. Nenhum método de imagem tem se mostrado eficaz em apresentar dados objetivos com relação ao tempo de recuperação dos atletas em casos de fraturas por estresse. Dois grupos foram incluídos no nosso estudo: grupo I consistente de 21 atletas com suspeita clínica de fratura de estresse (13 masculinos, idade média de $31,62 \pm 9,39)$ e grupo II consistente de 10 atletas sem sinais clínicos de fraturas de estresse (grupo controle) (seis masculinos, idade média 29,80 \pm 3,94). Todos os indivíduos do grupo I tiveram seguimento mínimo de seis meses e foram submetidos ao mesmo protocolo de reabilitação. Todos os atletas foram submetidos à ressonância magnética e cintilografia óssea com intervalo, entre os exames, inferior a sete dias. Um índice quantitativo foi obtido utilizando a técnica de ROI, comparando o lado afetado com o contralateral não afetado. Esta análise quantitativa foi comparada à análise semiquantitativa da ressonância magnética. 
Ambos os métodos mostraram $100 \%$ de sensibilidade; entretanto, sinais inespecíficos foram encontrados em $40 \%$ dos atletas assintomáticos na ressonância magnética e na cintilografia óssea. A média de captação de MDP-Tc99m na perna sintomática foi estatisticamente diferente no grupo I $(2,54 \pm 0,77)$ em comparação ao grupo II $(1,05 \pm 0,11)(p<0,001)$. Um índice de 1,30 foi considerado ponto crítico onde $99 \%$ dos atletas apresentarão diagnóstico de fratura de estresse. Uma equação de regressão foi obtida, associando o tempo de recuperação necessário para o atleta e o índice calculado. Na presente amostragem de pacientes, o índice obtido por meio da cintilografia óssea nos permite obter um método objetivo para estimar o apropriado tempo de recuperação após um diagnóstico de fratura por estresse da tíbia. Entretanto, mais estudos prospectivos, com maior amostragem, são necessários para comprovar nosso achado.

Descritores: (traumatismos em atletas, fraturas de estresse, cintilografia/classificação, imagem por ressonância magnética, prognóstico) 


\section{SUMMARY}

Castropil, W - Diagnostic and prognostic value of image methods in tibia stress fractures: clinical-radiological correlation. (Doutorado). São Paulo. Faculdade de Medicina, Universidade de São Paulo; 2006.

A major problem in athletes with stress fractures is the length of resting time required for complete recovery. No imaging tool has been capable of offering objective data regarding the appropriate recovery time in athletes with stress fractures. Two groups of athletes were included in our study: Group I consisted of 21 athletes with clinical suspicion of tibial stress fracture (13 male; mean age \pm SD: $31.62 \pm 9.39$ ) and, Group II consisted of 10 athletes without clinical signs of stress fracture (control group) (6 male; mean age \pm SD: $29.80 \pm 3.94)$. All individuals of Group I had minimum 6 months of follow up and the symptoms were recorded according to the same rehabilitation protocol. All athletes underwent to bone scintigraphy and MRI, with a mean interval between them no longer than 7 days. A quantitative index was obtained using $\mathrm{ROI}$ technique, comparing the affected to the non affected leg. This quantitative analysis was compared to a semi quantitative evaluation of MRI findings). Both methods showed $100 \%$ sensitivity; however, non specific signs were found in $40 \%$ of asymptomatic athletes either by MRI or by bone scan. The mean uptake of MDP-Tc99m in affected limbs were statistically different in Group I $(2.54 \pm 0.77)$ in comparison to Group II $(1.05 \pm 0.11)(p<0.001)$. An index of 1.30 was considered a critical point where $99 \%$ of athletes will present the clinical diagnosis of tibial stress fracture. 
A regression equation was obtained associating the time of recovery required for each athlete with the uptake index calculated. In the present sample of athletes the uptake index obtained through bone scintigraphy allowed us to obtain an objective method to estimate the appropriate recovering time after the tibial stress fracture diagnosis. However, more prospective studies using larger samples are needed to prove that assumption.

Keywords: (athletic injuries, stress fractures, radionuclide imaging/classification, magnetic resonance imaging, prognosis) 


\section{INTRODUÇÃO}

Quando Aristóteles (384-322 a.c.) proferiu a frase "os vitoriosos olímpicos são aqueles que não perdem seus poderes pelo treinamento excessivo", talvez se referisse às lesões por sobrecarga, que acometiam os atletas Olímpicos desde tempos remotos.

As lesões por sobrecarga são freqüentes na prática esportiva, podendo acometer todo o aparelho locomotor. Quando afetam os ossos, podem ter várias denominações: fraturas por sobrecarga, por fadiga, por insuficiência ou por estresse.

A primeira descrição da patologia vem do médico militar prussiano Breithaupt, que introduz o termo, descreve os sinais, os sintomas e a evolução da fratura de estresse do metatarso em 1855, antes do advento da radiografia (apud Stanitski et al.,1978).

Nas décadas de 1970 e 1980, com o aumento da freqüência e da intensidade da prática de atividade física, os diversos aspectos relacionados às fraturas por estresse passaram a ser estudados na população fisicamente ativa (Scully e Besterman, 1982; Matheson et al., 1987).

Com o diagnóstico clínico e a radiografia mostrando alterações somente na fase mais tardia da evolução, os estudos de imagem inicialmente eram limitados e pouco contribuíam para o estudo da patologia. 
A cintilografia óssea e a ressonância magnética trouxeram valiosas informações sobre anatomia e metabolismo ósseo nos pacientes com fraturas por estresse (Roub et al., 1979; Lee e Yao, 1988).

Ao tratarmos de pacientes com fraturas por estresse, temos que avaliar fatores intrínsecos predisponentes (anatômicos, encurtamentos musculares, hiperfrouxidão ligamentar) e extrínsecos, relacionados a erros de treinamento ou ao uso de equipamentos inadequados (Krivickas, 1997). Mas, quando tratamos de atletas, o maior questionamento se refere ao prognóstico, ou seja, faz-se necessário determinar, com precisão, o tempo de afastamento dos treinos e das competições para que o osso acometido recupere sua integridade estrutural e metabólica, permitindo que o atleta retorne à prática esportiva com mínimos riscos de recidiva ou de aparecimento de novas fraturas por estresse. Esta pergunta é fundamental para a reprogramação do ciclo de treinamento e, muitas vezes, interfere na programação da equipe.

Analisando atletas com diagnóstico de fraturas por estresse, com períodos de recuperação muito variáveis, observa-se escassez de dados de literatura que avaliem os métodos de imagem disponíveis com o objetivo de predizer o tempo adequado de afastamento e recuperação. Muito da avaliação atual baseia-se em dados subjetivos e essencialmente clínicos para estimar se o atleta poderá continuar com cargas progressivas de esforço.

A cintilografia, por analisar o metabolismo ósseo aumentado nestes pacientes, é o exame que indica as alterações iniciais, apresenta grande 
sensibilidade e auxilia no diagnóstico precoce da patologia (Prather et al., 1977). Uma das limitações da cintilografia é a especificidade, pois qualquer injúria óssea, mesmo que não resulte em fratura, pode mostrar reação metabólica óssea. Outro aspecto complicador da cintilografia é que fraturas antigas podem demorar a demonstrar resolução metabólica, e imagens funcionais positivas nem sempre irão representar fraturas recentes.

A classificação cintilográfica descrita por Zwas et al. (1987) apresenta uma proposta de acometimento ósseo utilizada até hoje e faz uma relação da mesma com tempo de afastamento de atividades de impacto, levando em consideração apenas a extensão da hipercaptação na cintilografia óssea, sem avaliar sua intensidade. Essa extensão é baseada, também, na quantidade de osso acometido no plano transversal, não incorporando outros parâmetros de extensão como o grau de comprometimento no plano coronal ou longitudinal.

Com a introdução da ressonância magnética como método de diagnóstico complementar das fraturas de estresse, valiosas informações da anatomia óssea e de partes moles ao redor do sítio de fratura puderam ser analisadas, em muitos casos distinguindo patologias e contribuindo para o diagnóstico diferencial (Lee e Yao, 1988). A ressonância magnética se caracteriza por demonstrar edema periosteal e por vezes é possível identificar a linha de fratura nos casos mais avançados. Portanto, nem todo achado de edema ósseo ou periosteal é representativo de fratura óssea por estresse, e isso pode comprometer a especificidade da ressonância magnética. 
O estudo de Fredericson et al. (1995) classifica as fraturas de estresse de tíbia por meio de ressonância magnética e associa o tempo de recuperação aos quatro graus de acometimento ósseo, tornando-se hoje valioso instrumento para avaliação do prognóstico nos casos de fraturas por estresse, mas não encontra correlação entre a classificação proposta e a utilizada por Zwas et al. (1987).

Apesar do número crescente de estudos neste campo, poucos correlacionam cintilografia óssea e ressonância magnética. É ainda mais restrito o número de estudos que procuram encontrar uma classificação para orientar o melhor tratamento, indicando ao atleta o tempo de afastamento de seus treinos.

Nosso estudo foi motivado pela dificuldade em obter critérios objetivos de avaliação do grau de acometimento ósseo em pacientes com diagnóstico clínico de fraturas por estresse, que pudessem ao mesmo tempo definir o tempo ideal de repouso e de recuperação total. 


\section{SUMMARY}

Castropil, W - Diagnostic and prognostic value of image methods in tibia stress fractures: clinical-radiological correlation. (Doutorado). São Paulo. Faculdade de Medicina, Universidade de São Paulo; 2006.

A major problem in athletes with stress fractures is the length of resting time required for complete recovery. No imaging tool has been capable of offering objective data regarding the appropriate recovery time in athletes with stress fractures. Two groups of athletes were included in our study: Group I consisted of 21 athletes with clinical suspicion of tibial stress fracture (13 male; mean age \pm SD: $31.62 \pm 9.39$ ) and, Group II consisted of 10 athletes without clinical signs of stress fracture (control group) (6 male; mean age \pm SD: $29.80 \pm 3.94)$. All individuals of Group I had minimum 6 months of follow up and the symptoms were recorded according to the same rehabilitation protocol. All athletes underwent to bone scintigraphy and MRI, with a mean interval between them no longer than 7 days. A quantitative index was obtained using $\mathrm{ROI}$ technique, comparing the affected to the non affected leg. This quantitative analysis was compared to a semi quantitative evaluation of MRI findings). Both methods showed $100 \%$ sensitivity; however, non specific signs were found in $40 \%$ of asymptomatic athletes either by MRI or by bone scan. The mean uptake of MDP-Tc99m in affected limbs were statistically different in Group I $(2.54 \pm 0.77)$ in comparison to Group II $(1.05 \pm 0.11)(p<0.001)$. An index of 1.30 was considered a critical point where $99 \%$ of athletes will present the clinical diagnosis of tibial stress fracture. 
A regression equation was obtained associating the time of recovery required for each athlete with the uptake index calculated. In the present sample of athletes the uptake index obtained through bone scintigraphy allowed us to obtain an objective method to estimate the appropriate recovering time after the tibial stress fracture diagnosis. However, more prospective studies using larger samples are needed to prove that assumption.

Keywords: (athletic injuries, stress fractures, radionuclide imaging/classification, magnetic resonance imaging, prognosis) 


\section{INTRODUÇÃO}

Quando Aristóteles (384-322 a.c.) proferiu a frase "os vitoriosos olímpicos são aqueles que não perdem seus poderes pelo treinamento excessivo", talvez se referisse às lesões por sobrecarga, que acometiam os atletas Olímpicos desde tempos remotos.

As lesões por sobrecarga são freqüentes na prática esportiva, podendo acometer todo o aparelho locomotor. Quando afetam os ossos, podem ter várias denominações: fraturas por sobrecarga, por fadiga, por insuficiência ou por estresse.

A primeira descrição da patologia vem do médico militar prussiano Breithaupt, que introduz o termo, descreve os sinais, os sintomas e a evolução da fratura de estresse do metatarso em 1855, antes do advento da radiografia (apud Stanitski et al.,1978).

Nas décadas de 1970 e 1980, com o aumento da freqüência e da intensidade da prática de atividade física, os diversos aspectos relacionados às fraturas por estresse passaram a ser estudados na população fisicamente ativa (Scully e Besterman, 1982; Matheson et al., 1987).

Com o diagnóstico clínico e a radiografia mostrando alterações somente na fase mais tardia da evolução, os estudos de imagem inicialmente eram limitados e pouco contribuíam para o estudo da patologia. 
A cintilografia óssea e a ressonância magnética trouxeram valiosas informações sobre anatomia e metabolismo ósseo nos pacientes com fraturas por estresse (Roub et al., 1979; Lee e Yao, 1988).

Ao tratarmos de pacientes com fraturas por estresse, temos que avaliar fatores intrínsecos predisponentes (anatômicos, encurtamentos musculares, hiperfrouxidão ligamentar) e extrínsecos, relacionados a erros de treinamento ou ao uso de equipamentos inadequados (Krivickas, 1997). Mas, quando tratamos de atletas, o maior questionamento se refere ao prognóstico, ou seja, faz-se necessário determinar, com precisão, o tempo de afastamento dos treinos e das competições para que o osso acometido recupere sua integridade estrutural e metabólica, permitindo que o atleta retorne à prática esportiva com mínimos riscos de recidiva ou de aparecimento de novas fraturas por estresse. Esta pergunta é fundamental para a reprogramação do ciclo de treinamento e, muitas vezes, interfere na programação da equipe.

Analisando atletas com diagnóstico de fraturas por estresse, com períodos de recuperação muito variáveis, observa-se escassez de dados de literatura que avaliem os métodos de imagem disponíveis com o objetivo de predizer o tempo adequado de afastamento e recuperação. Muito da avaliação atual baseia-se em dados subjetivos e essencialmente clínicos para estimar se o atleta poderá continuar com cargas progressivas de esforço.

A cintilografia, por analisar o metabolismo ósseo aumentado nestes pacientes, é o exame que indica as alterações iniciais, apresenta grande 
sensibilidade e auxilia no diagnóstico precoce da patologia (Prather et al., 1977). Uma das limitações da cintilografia é a especificidade, pois qualquer injúria óssea, mesmo que não resulte em fratura, pode mostrar reação metabólica óssea. Outro aspecto complicador da cintilografia é que fraturas antigas podem demorar a demonstrar resolução metabólica, e imagens funcionais positivas nem sempre irão representar fraturas recentes.

A classificação cintilográfica descrita por Zwas et al. (1987) apresenta uma proposta de acometimento ósseo utilizada até hoje e faz uma relação da mesma com tempo de afastamento de atividades de impacto, levando em consideração apenas a extensão da hipercaptação na cintilografia óssea, sem avaliar sua intensidade. Essa extensão é baseada, também, na quantidade de osso acometido no plano transversal, não incorporando outros parâmetros de extensão como o grau de comprometimento no plano coronal ou longitudinal.

Com a introdução da ressonância magnética como método de diagnóstico complementar das fraturas de estresse, valiosas informações da anatomia óssea e de partes moles ao redor do sítio de fratura puderam ser analisadas, em muitos casos distinguindo patologias e contribuindo para o diagnóstico diferencial (Lee e Yao, 1988). A ressonância magnética se caracteriza por demonstrar edema periosteal e por vezes é possível identificar a linha de fratura nos casos mais avançados. Portanto, nem todo achado de edema ósseo ou periosteal é representativo de fratura óssea por estresse, e isso pode comprometer a especificidade da ressonância magnética. 
O estudo de Fredericson et al. (1995) classifica as fraturas de estresse de tíbia por meio de ressonância magnética e associa o tempo de recuperação aos quatro graus de acometimento ósseo, tornando-se hoje valioso instrumento para avaliação do prognóstico nos casos de fraturas por estresse, mas não encontra correlação entre a classificação proposta e a utilizada por Zwas et al. (1987).

Apesar do número crescente de estudos neste campo, poucos correlacionam cintilografia óssea e ressonância magnética. É ainda mais restrito o número de estudos que procuram encontrar uma classificação para orientar o melhor tratamento, indicando ao atleta o tempo de afastamento de seus treinos.

Nosso estudo foi motivado pela dificuldade em obter critérios objetivos de avaliação do grau de acometimento ósseo em pacientes com diagnóstico clínico de fraturas por estresse, que pudessem ao mesmo tempo definir o tempo ideal de repouso e de recuperação total. 


\section{OBJETIVO}

O presente estudo teve por objetivos:

1) Comparar ressonância magnética e cintilografia no diagnóstico das fraturas de estresse;

2) Estabelecer um critério de graduação do acometimento ósseo nas fraturas de estresse que permita uma correlação entre os dois métodos de imagem;

3) Avaliar o valor prognóstico do critério de graduação proposto no acompanhamento das fraturas de estresse. 


\section{REVISÃO DA LITERATURA}

\subsection{Aspectos Clínicos}

Breithaupt (apud Stanitski, 1978) é o médico militar prussiano que primeiro descreve a fratura de estresse em recrutas com pés doloridos e edematosos após longas marchas.

Hartley (1942) reporta a história, localização, idade e sexo de 14 pacientes com diagnóstico clínico de fraturas por estresse na tíbia, sendo três bilaterais e acometendo o terço proximal e médio da tíbia. Aponta a patologia como decorrente da fadiga e reconhece a necessidade do diagnóstico precoce para evitar o risco de fratura completa.

Burrows (1956) descreve seis casos de fraturas por fadiga no córtex anterior do terço médio da tíbia em dançarinos de ballet. Avalia os pacientes por meio de exames de sangue, radiografia simples e biópsia em dois casos. Conclui que a patologia é localizada, com exames de sangue normais em todos os casos, traço de fratura incompleta no córtex anterior da tíbia ao exame de radiografia simples e ausência de formação de calo ósseo em osso normal ao exame anátomo-patológico. 
Devas (1958) faz revisão da literatura entre os anos de 1938 e 1958, apresentando os dados epidemiológicos de 78 pacientes com fraturas de estresse. Analisa com detalhes 16 casos de fraturas de estresse na tíbia e é o primeiro a relacionar estes casos com "shin splint", descrevendo o início insidioso da patologia, que progride até acarretar impossibilidade de prática esportiva ao atleta. Apresenta, também, as dificuldades de diagnóstico por meio dos métodos de imagem disponíveis na época, aponta a força da musculatura da panturrilha como fator causal da patologia e o afastamento de qualquer atividade que reproduza a dor como a parte importante do tratamento.

Devas (1960) descreve a variação de fratura de estresse de tíbia em seis casos de fratura no terço distal, longitudinal, que se inicia no córtex póstero-medial e tem direção superior e lateral.

Stanitski et al. (1978) revêem 17 casos de fraturas de estresse, analisando a história, exame físico e propõem modelo de patofisiologia. Apresentam a fratura de estresse como patologia descrita em apenas três animais: cavalos e cachorros de corrida e humanos, todos associados com treinos objetivando máximo rendimento em determinada atividade específica ritmada. Correlacionam o aparecimento da fratura por estresse a contrações musculares ritmadas e repetidas em determinado sítio ósseo, gerando agressão mecânica no foco da fratura. 
Orava (1980) analisa os dados de 185 fraturas por estresse estudados prospectivamente durante um período de dez anos. Embora de distribuição variada, relata predominância dos casos na tíbia em 106 casos, e tempo de repouso para retorno à atividade física de quatro a seis semanas, quando a diáfise da tíbia é acometida, e de oito a dez semanas para o acometimento da tîbia proximal.

Mubarak et al. (1982) estudam a síndrome de estresse tibial em 12 pacientes, avaliando a pressão compartimental, mobilidade da subtalar, radiografia e cintilografia e a biópsia em dois casos. Encontram valores normais de pressão compartimental e aumentados de mobilidade da articulação subtalar. Concluem que a síndrome de estresse tibial é decorrente de uma periostite local por tração e não recomendam fasciotomia como tratamento desta patologia.

Scully e Besterman (1982) descrevem treinamento preventivo baseado em aspectos biomecânicos e biodinâmicos da resposta do osso ao treinamento. Apresentam proposta de mudança no treinamento com eliminação dos treinos de saltos, corrida e impacto na terceira semana do treino básico militar. Encontram incidência de fratura por estresse em 1,6\% deste grupo, enquanto o grupo controle apresenta incidência de 4,8\%, sem alteração do resultado do teste físico ao final do programa de treinos. 
Viitasalo e Kvist (1983) realizam estudo biomecânico em dois grupos de corredores: com e sem síndrome de estresse medial da tíbia, analisando os aspectos de mobilidade da articulação subtalar e do tornozelo. Encontram diferenças estatisticamente significantes entre os dois grupos, com o grupo de estresse tibial apresentando maior mobilidade da subtalar, tanto em inversão quanto em eversão, e maior amplitude de movimentos do tornozelo.

Michael e Holder (1985) realizam dissecção anatômica em 14 cadáveres (28 pernas) e eletromiografia em 10 pacientes, objetivando estudar a síndrome de estresse medial na tíbia. Encontram relação entre a fáscia do músculo sóleo, estrutura anatômica e biomecanicamente responsável pela produção de estresse na região, especialmente quando o tornozelo encontra-se em pronação. Recomendam a descompressão desta fáscia em casos cujos pacientes não obtêm melhora com as medidas conservadoras de tratamento.

Matheson et al. (1987) estudam clinicamente 320 casos de fraturas de estresse por meio de radiografias simples em $43,4 \%$ dos casos e cintilografia óssea em $64,4 \%$ dos pacientes. Encontram como local de acometimento mais freqüente a tíbia (em $49,1 \%$ dos casos), bilateralidade em $16,6 \%$ dos casos e diferença estatisticamente significante em relação à idade, sendo tíbia e fíbula mais afetadas nos jovens e o fêmur e os metatarsos nos idosos. Relacionam o pé cavo com as fraturas de estresse 
de metatarsos e fêmur, e o pé plano às fraturas de estresse de tíbia e fíbula, havendo maior incidência nos corredores de longa distância.

Barrow e Saha (1988) analisam os dados de 240 questionários distribuídos a atletas colegiais corredoras de longa distância. Esses autores encontram correlação entre fraturas de estresse e alterações menstruais (49\% das corredoras com oligoamenorréria apresentam casos de fraturas de estresse), de maior gravidade quando associadas a distúrbios alimentares (presentes em $20 \%$ dos casos).

Rettig et al. (1988) descrevem e apresentam a história natural de oito atletas com fraturas por estresse no córtex anterior da tíbia. Alertam para as características particulares deste tipo de fratura e a complicações, como retardo de consolidação e pseudoartrose. Aconselham período de tratamento prolongado (de três a seis meses) e consideram que intervenções cirúrgicas podem ser necessárias.

Whitelaw et al. (1989) realizam estudo em que aplicam imobilizador pneumático em 42 pacientes com fratura de estresse na tíbia e encontram benefícios do uso deste imobilizador com menor sintomatologia e tempo de retorno às atividades diárias e ao esporte. Estes mesmos autores creditam o sucesso do tratamento ao menor estresse transmitido ao osso em fase de recuperação e também à melhoria no sistema venoso decorrente da compressão uniforme. 
Burr et al. (1990) induzem fraturas por estresse na tíbia de 31 coelhos, submetendo-os a forças repetidas e progressivas em modelo experimental, acompanhando-os durante três a nove semanas por meio de radiografia simples e cintilografia. Concluem que as fraturas por estresse podem ser obtidas após três a seis semanas de impacto, e encontram correlação positiva entre achados na radiografia e alterações na cintilografia óssea.

Giladi et al. (1991) acompanham prospectivamente 312 recrutas em busca de fatores de risco intrínsecos para fraturas por estresse. Os recrutas foram avaliados antes e acompanhados rotineiramente durante 14 semanas de treinamento preparatório. A avaliação inicial foi composta de exame físico ortopédico, radiografias dos pés e das tíbias, medidas biométricas dos membros inferiores, densidade óssea, capacidade aeróbica e de força e potência muscular de membros inferiores, somatótipo, hábitos e perfil social e psicológico. Encontraram dois fatores de risco estatisticamente significantes: tíbia mais estreita e maior ângulo de rotação externa do quadril. Estas variáveis foram independentes e cumulativas e a morbidade variou de $17 \%$ na ausência destas características, 29\% com a presença de uma delas e $45 \%$ quando as duas estavam presentes, o que pode explicar a susceptibilidade de alguns pacientes a fraturas por estresse. 
Monteleone (1995) faz extensa revisão de literatura, destacando a incidência, fatores de risco, diagnóstico e conduta. Encontra grande controvérsia quanto à incidência nos estudos avaliados, variando de menos de $2 \%$ a cerca de $31 \%$. Aponta idade, sexo e raça como fatores de risco, mostrando maior incidência nas mulheres, nos pacientes de mais idade e na raça branca. Apresenta a tíbia como a localização mais freqüente, responsável por cerca de $50 \%$ dos casos de fraturas de estresse e conclui que o tratamento conservador é eficaz, ressaltando a necessidade da correção dos fatores de risco e medidas preventivas.

Bennell et al. (1996a) estudam prospectivamente por 12 meses a incidência e a distribuição das fraturas de estresse em 111 atletas de atletismo (53 mulheres e 58 homens). Encontram 20 casos de fraturas de estresse, com incidência de 0,7 lesões em 1.000 horas de treino (sem diferença significativa entre homens e mulheres). As fraturas são mais freqüentes no inverno ( $50 \%$ dos casos) e atletas de longa distância são mais acometidos por fraturas em ossos longos, enquanto atletas de explosão (velocistas e saltadores) apresentaram maior acometimento nos pés, mas 0 local de acometimento mais freqüente é a tíbia ( $46 \%$ dos casos). Concluem que fatores predisponentes devem ser avaliados nesses atletas, pela alta incidência de fraturas de estresse e pela recorrência da patologia (história pregressa da patologia em pacientes que apresentam fraturas por estresse). 
Em estudo complementar realizado na mesma população, Bennell et al. (1996b) procuram estabelecer os fatores de risco para fratura de estresse, analisando densidade mineral óssea, composição corporal e medidas antropométricas. Concluem que as mulheres apresentam, como fatores independentes preditivos para fratura de estresse, a idade de menarca (maior que 14 anos) e a circunferência da panturrilha (menor que $32,2 \mathrm{~cm})$. Não encontram fatores de risco para a população do sexo masculino.

Ballas et al. (1997) avaliam as principais lesões de sobrecarga em corredores e descrevem as fraturas de estresse, responsáveis por 9,3\% dos casos, como a segunda maior causa de problemas (atrás apenas da síndrome fêmuro-patelar). Analisam a etiologia das lesões, dividindo-a entre fatores intrínsecos e extrínsecos, relatando a importância da correção destes fatores como parte do tratamento. Como fatores extrínsecos descrevem erros de treinamento, calçados gastos ou inadequados ou tipo de piso, e recomendam correr no máximo 45 milhas por semana, progredir $10 \%$ da carga de treinos por semana e trocar o calçado a cada 500 milhas. Como principais fatores intrínsecos apontam a deficiência de alongamento e os pés hiperpronadores, sugerindo o uso de órteses e o alongamento cuidadoso como medidas eficazes na prevenção da patologia.

Krivickas (1997) faz ampla revisão da literatura referente a fatores predisponentes de lesões por sobrecarga e aponta como fatores 
relacionados à fratura por estresse: o sexo feminino, em especial quando há amenorréia associada, o alinhamento em varo do membro inferior e a pronação excessiva dos pés.

Swenson et al. (1997) estudam de forma randomizada e prospectiva os efeitos de um suporte pneumático no tempo de tratamento de pacientes com fratura de estresse. Analisam 18 pacientes com fratura de estresse na tíbia, com diagnóstico clínico e confirmado por meio de cintilografia óssea, divididos em dois grupos: com e sem o uso de suporte pneumático. Encontram diminuição do tempo de tratamento no grupo que utiliza o suporte, com menor tempo de retorno à atividade física (21dias) quando comparado ao grupo controle (77 dias). Apresentam programa de retorno progressivo à prática esportiva em cinco estágios, desde a caminhada até o retorno ao esporte específico sem restrições.

Crossley et al. (1999) analisam 46 corredores de longa distância masculinos, subdivididos em dois grupos (com e sem fraturas por estresse na tíbia). Realizam análise biomecânica em plataforma de força, analisam a geometria da tíbia por meio de tomografia computadorizada e avaliam a densidade mineral óssea da tíbia. Encontram associação de fratura por estresse com a geometria da tíbia, sendo que o grupo com fratura de estresse apresenta tíbia com menor área seccional que o grupo sem fratura, após ajustes feitos em relação ao peso corporal e altura. Não encontram 
associação da patologia com densidade mineral ou análises biomecânicas feitas na plataforma de força.

Finestone et al. (1999) apresentam estudo prospectivo em que avaliam a incidência de fraturas por estresse em três grupos, durante 14 semanas de treinamentro básico militar: com a utilização de palmilhas semirígidas, de palmilhas macias feitas sob medida e sem o uso de palmilhas. Encontram incidência de fraturas por estresse de 15,7\% nos recrutas com o uso das palmilhas semi-rígidas, $10,7 \%$ para os recrutas com a palmilha macia e $27 \%$ para o grupo controle. Defendem o uso preventivo de palmilhas, especialmente em pacientes de maior risco para o desenvolvimento de fraturas de estresse.

Boden e Oshahr (2001) estudam as fraturas de estresse de alto risco do ponto de vista de localização e tratamento. Apontam como locais de alto risco: colo femural no lado de tensão, patela, córtex anterior da tíbia, maléolo medial, tálus, navicular, quinto metatarso e sesamóides. Nas fraturas de alto risco recomendam tratamento mais agressivo, com períodos de afastamento mais longos e tratamento cirúrgico, se necessário. Nas fraturas do córtex anterior da tíbia, preconizam afastamento por 4 a 6 meses e, se houver fissura, recomendam cirurgia para implantação de pino intramedular.

Boden et al. (2001) descrevem que as fraturas por estresse podem ocorrer em todos os ossos, sendo mais acometidos os de carga de membros 
inferiores e analisam as fraturas de baixo risco. Apresentam a tíbia como o local de acometimento mais freqüente $(49,1 \%$ dos casos) e concluem que o diagnóstico é feito a partir de história e exame físico, sendo a cintilografia óssea necessária, apenas em alguns casos, na pelve e coluna lombar. Relatam que a incidência de fraturas de estresse na população geral de atletas é menor que $1 \%$, porém a incidência em corredores pode ser maior que $15 \%$. Definem a fratura por estresse como resultado de carga excessiva e repetitiva sobre o osso, causando desequilíbrio entre o metabolismo de reabsorção e a formação óssea, e descrevem o aumento repentino na quantidade ou na intensidade do exercício como a causa mais comum de fraturas por estresse.

Korpelainen et al. (2001) estudam os fatores predisponentes para fraturas de estresse, analisando aspectos antropométricos e biomecânicos de 31 atletas com fraturas de estresse recidivadas ou múltiplas em comparação com 15 atletas controle assintomáticos e sem diagnóstico prévio de fraturas de estresse. Encontram correlação positiva com pés cavos, antepé varo, discrepância de membros inferiores e alterações menstruais nas mulheres.

Milgrom et al. (2003) realizam estudo biomecânico comparativo entre corrida no solo e corrida na esteira em dois corredores recreacionais voluntários (um masculino e um feminino). Encontram níveis de estresse, compressão e tensão significativamente menores na corrida em esteira do 
que na corrida no solo, e recomendam esta modalidade em corredores recreacionais que desejam reduzir riscos ou nos casos de retorno após período de afastamento em decorrência do tratamento de uma lesão.

Shaffer et al. (2005) analisam os dados epidemiológicos e clínicos de 2.962 recrutas no início do treinamento militar e fazem acompanhamento prospectivo durante um ano. Encontram 181 casos de fraturas por estresse (5,1\%), cuja localização preferencial é a tíbia (25\%) e apontam dois fatores de risco: baixa capacidade aeróbica e alterações menstruais. Concluem que atletas com estes fatores de risco devem ficar sob observação mais rigorosa e que modificações no treinamento deste grupo podem resultar em menor incidência de fraturas por estresse. 


\subsection{Aspectos Radiológicos}

Savoca (1971) apresenta a classificação dos primeiros sinais de fraturas por estresse na radiografia simples, associando as alterações à patofisiologia. Descreve, como sinais precoces, a esclerose na metáfise dos ossos longos e a reação periosteal ou fratura cortical na diáfise dos ossos longos.

Citrin et al. (1974) descrevem a técnica de avaliação quantitativa na cintilografia óssea, comparando a hipercaptação na área afetada por tumores ósseos com o lado contralateral normal. Testam a metodologia em diversas áreas, tempos diferentes e entre observadores, concluindo que é metodologia simples, sem custo adicional, reprodutível e que pode ser utilizada para avaliação do resultado no tratamento de tumores ósseos.

Prather et al. (1977) avaliam 42 pacientes com suspeita clínica de fraturas por estresse por meio de radiografia simples e cintilografia óssea. $\bigcirc$ diagnóstico final de fratura de estresse foi feito em 21 pacientes e, em 15 deles, a radiografia foi considerada normal, resultando em $71 \%$ de falsosnegativos. Encontraram cintilografia positiva em todos os casos de fraturas por estresse (ausência de falsos-negativos) e positividade do método em cinco pacientes, por outras causas (24\% de falsos-positivos). 
Roub et al. (1979) realizam estudo por meio de radiografia simples e cintilografia óssea, analisando 35 pacientes com dor na perna em decorrência de atividade física comparados com o lado contralateral e com 13 voluntários assintomáticos. As alterações foram encontradas sempre no aspecto medial da tíbia, podendo variar de bem definidas e ovaladas até fusiformes e mal definidas, sem correlação entre o aparecimento de traço de fratura e a radiografia. Concluem que o termo fratura de estresse pode abranger toda a patologia, representando estágios evolutivos de estresse medial à tíbia.

Daffner at al. (1982) discutem os métodos de imagem no diagnóstico e na avaliação das fraturas por estresse, relatando a importância da cintilografia como método de detecção precoce, além de revelar pontos de estresse em locais assintomáticos.

Greaney et al. (1983) encontram 839 alterações cintilográficas em 250 pacientes que procuraram o serviço médico com queixa de dores, por estresse, nos membros inferiores. Apresentam análise epidemiológica dos dados, com predominância na tíbia em $49 \%$ dos casos (sendo o terço proximal o mais acometido), e propõem que a alteração na cintilografia óssea associada ao sintoma no local de estresse deva ser considerado critério definitivo de diagnóstico de uma fratura de estresse. Classificam as alterações na cintilografia óssea em graus, variando de zero (normal) a 3+, de forma subjetiva, baseada na intensidade de sinal, e não encontram 
correlação entre a graduação proposta e as alterações na radiografia simples.

Groshar et al. (1985) realizam cintilografias ósseas em recrutas submetidos a intenso treinamento militar. Encontram 124 locais de aumento focal de captação em 64 recrutas, dos quais 32 são completamente assintomáticos. Em 38 recrutas (59\%) encontram múltiplos focos de aumento de captação. Três recrutas apresentaram sintomatologia dolorosa 7 a 14 dias após a realização da cintilografia, e os autores sugerem que o diagnóstico de fratura de estresse deva ser feito quando houver aumento de captação, admitindo que a dor possa vir após algum tempo.

Chisin et al. (1987) estudam o significado clínico das alterações não focais da cintilografia óssea nas fraturas de estresse. Avaliam, para tanto, os dados de 27 recrutas com história clínica de fraturas por estresse submetidos à cintilografia óssea e classificam os achados em quatro níveis: grau 1, sendo aumento de sinal em relação ao lado contralateral em área mal definida; grau 2, com maior intensidade e extensão em área mal definida; grau 3 aumento de sinal em relação ao lado contra-lateral, de formato fusiforme ou ovalado, com bordas bem definidas; e grau 4, semelhante ao grau anterior, com aumento de sinal comparável à crista ilíaca. Analisam em detalhes 14 pacientes com lesões consideradas não focais (grau 1 e 2) e não encontram relação deste achado com a evolução para fratura por estresse. Em oito casos os achados involuíram a despeito 
da continuidade dos treinamentos e, em quatro, evoluíram para fraturas por estresse. Recomendam a descontinuidade dos treinamentos por curto período e atenção especial ao sítio doloroso nestes casos antes do retorno aos treinos.

Zwas et al. (1987) analisam os dados de cintilografias ósseas realizadas em 310 militares recrutas, submetidos a treinamento militar. Encontram 391 alterações cintilográficas em 235 recrutas, sendo 40\% assintomáticos. Propõem sistema de graduação das lesões em quatro níveis baseados na dimensão e extensão da lesão e concentração do fármaco. Apresentam correlação entre o sistema proposto e o tempo de repouso necessário para o tratamento.

Lee e Yao (1988) descrevem os achados da ressonância magnética em cinco casos de fraturas por estresse com diagnóstico clínico e confirmados por meio de cintilografia óssea. Como achados mais característicos de fratura de estresse à ressonância magnética, indicam o menor sinal nas imagens pesadas em T1 e hipersinal na medular óssea, nas imagens pesadas em T2.

Nielsen et al. (1991) realizam radiografia simples e cintilografia em 29 tíbias com dor à palpação da borda póstero-medial, e cintilografias de controle em 12. Classificam as imagens em cinco estágios ( 0 a V), dependendo da porcentagem do osso acometido, sem diferenciação entre 
fraturas de estresse e síndrome de estresse tibial. Encontram 24 lesões sintomáticas e 5 assintomáticas, e alta correlação entre os achados radiográficos e as lesões estágio III, baixa com o estágio II e nenhuma com o estágio 0. Recomendam a realização da cintilografia para avaliação destas lesões devido à alta sensibilidade, detecção precoce, mas desaconselham o seu uso para acompanhamento, pois a mesma permanece alterada por vários meses, sendo os sinais clínicos e o nível de dor as bases para o seguimento.

Fredericson et al. (1995) analisam os dados de 14 pacientes com achados de 18 fraturas de estresse na tíbia, submetidos à ressonância magnética e cintilografia óssea, objetivando comparar os métodos e estabelecer parâmetros prognósticos. Apresentam graduação das fraturas de estresse baseados na ressonância magnética e relacionam esta classificação com tempo de retorno à atividade esportiva, propondo protocolo de reabilitação para cada fase. Consideram a ressonância magnética superior à cintilografia óssea em termos de precisão e como valor de predição de retorno do atleta a atividades esportivas.

Etchebehere et al. (1998) defendem as vantagens de utilização da cintilografia óssea nas patologias ortopédicas de membros inferiores. Como principais aplicações citam a avaliação da fise em traumas de crianças, avaliação precoce de alterações degenerativas articulares, nos pósoperatórios de artroplastias e nos casos de fraturas por estresse. 
Recomendam a avaliação quantitativa pela cintilografia óssea como método de predição da evolução do crescimento do membro após trauma em pacientes com fise aberta.

Shearman et al. (1998) descrevem oito casos e apresentam revisão de literatura das fraturas por estresse longitudinais da tíbia. Indicam a radiografia simples como método de imagem inicial, podendo ser negativa em $25 \%$ dos casos. A cintilografia foi positiva em $100 \%$ dos casos, e concluem que a tomografia computadorizada e a ressonância magnética podem ser necessárias para melhor avaliação da configuração do traço de fratura, quando visível pela técnica empregada.

Kiuru et al. (2001) estudam 30 pacientes apresentando 37 fraturas de estresse por meio de ressonância magnética com a utilização de contraste paramagnético (gadolíneo), com o objetivo de avaliar este método nas fraturas de estresse da pélvis e membros inferiores. Consideram importante a administração de contraste para analisar a perfusão tecidual, o calo ósseo e o edema muscular. Correlacionam o aumento da concentração do fármaco à presença de calo ósseo, traço de fratura ou edema muscular. Os autores, assim, propõem um sistema de graduação em cinco níveis, baseado no método de ressonância magnética com a utilização de contraste paramagnético. 
Dutton et al. (2002) avaliam, retrospectivamente, 58 recrutas com diagnóstico clínico de fraturas de estresse submetidos a cintilografia óssea. Utilizam sistema de classificação proposto por Zwas et al. (1987) e analisam o tempo de retorno à atividade física e abandono do treinamento em decorrência de dor. Não encontram correlação entre o grau de acometimento ósseo, segundo a classificação utilizada, e o tempo de retorno ou abandono do treinamento.

Kiuru et al. (2002) comparam ressonância magnética e cintilografia óssea em duas fases no diagnóstico das fraturas de estresse na pélvis e membros inferiores. Avaliam, prospectivamente, 50 pacientes com diagnóstico clínico de fraturas por estresse submetidos a ambos os métodos de imagem. Concluem que a ressonância magnética é mais sensível que a cintilografia óssea em duas fases na avaliação das fraturas de estresse e consideram que esta deva ser o método de escolha no diagnóstico complementar.

Ishibashi et al. (2002) realizam estudo prospectivo, comparando ressonância magnética e cintilografia óssea realizadas em 31 pacientes com suspeita clínica de fraturas por estresse. Encontram similaridade entre os métodos, no que diz respeito à sensibilidade e especificidade, e recomendam que se escolha a ressonância magnética, por ser menos invasiva e apresentar informações adicionais sobre as partes moles. 
Pozderac (2002) reporta três casos de fraturas de estresse longitudinal da tíbia, analisando suas características. O diagnóstico foi feito por meio de cintilografia óssea, que demonstra hipercaptação no terço distal, estendendo-se desde a junção tibio-fibular distal; porém o autor recomenda o uso da tomografia computadorizada para seu acompanhamento, devido ao custo e avaliação ortogonal do traço de fratura.

Spitz e Newberg (2002) discutem o mecanismo, os achados clínicos e de métodos de imagem nas fraturas de estresse. Apontam a alta sensibilidade da cintilografia óssea como importante fator a ser considerado na escolha deste método, mas ressaltam que o método não é indicado para seguimento, uma vez que pode permanecer alterado por longos períodos.

Arendt et al. (2003) fazem análise retrospectiva de dez anos das lesões por sobrecarga no osso de atletas colegiais. Encontram 74 casos de fraturas de estresse, com confirmação diagnóstica por meio de ressonância magnética, em 61 casos, e cintilografia óssea, em apenas um paciente. Descrevem uma incidência predominante na tíbia (37\%) e utilizam o sistema de graduação descrito por Fredericson et al. (1995). Apresentam protocolo de reabilitação em quatro fases. A fase I identifica o paciente com dor à deambulação e o mesmo é orientado a utilizar muletas, podendo realizar apenas natação como atividade física. A fase II se inicia quando o paciente tem condições de deambular sem dor e consiste em bicicleta, elíptico e exercícios de fortalecimento e de impacto apenas na água. A fase III indica 
início das atividades de impacto por 2 a 3 minutos, em dias alternados, e exercícios de fortalecimento com sobrecarga. Na fase IV é introduzido o esporte específico em cargas progressivas e em dias alternados. A qualquer momento o paciente é orientado a retornar à fase anterior, caso apresente dor. Os autores encontram correlação entre o grau de acometimento ósseo na ressonância magnética e o tempo de retorno à prática de atividade física.

Gaeta et al. (2005) realizam estudo comparativo entre tomografia computadorizada, ressonância magnética e cintilografia óssea em atletas com lesões por esforço repetitivo na tíbia. Analisam as imagens dos três métodos em 42 pacientes com 50 lesões (oito bilaterais). Todos apresentavam dor na tíbia com até um mês de início dos sintomas e foram comparados com dez voluntários assintomáticos. Apresentam sensibilidade de $88 \%$ para a ressonância magnética, $42 \%$ para a tomografia e $74 \%$ para a cintilografia óssea. 


\section{MÉTODOS}

\subsection{Casuística}

Analisaram-se 21 pacientes que, de forma prospectiva, foram atendidos com diagnóstico clínico de fratura por estresse na tíbia, no período de julho de 2002 a janeiro de 2005.

Adotaram-se como critérios de inclusão pacientes de qualquer idade, sexo ou cor, com sintomatologia, epidemiologia e quadro clínico sugestivos de fratura por estresse de tíbia. Todos os pacientes foram submetidos a exame complementar de cintilografia óssea e ressonância magnética em intervalo não superior a uma semana entre os métodos.

Como critérios de exclusão estabeleceram-se pacientes em período gestacional ou em processo de lactação, e atletas que não pudessem se comprometer com o prazo mínimo de seis meses de seguimento clínico.

A relação dos atletas e suas características estão apresentadas na tabela 1 e passaremos a denominá-los de grupo I. A descrição completa da casuística e resultados do grupo I está apresentada no anexo 2.

Realizamos os exames de ressonância magnética e cintilografia óssea, nos mesmos moldes, em dez atletas voluntários assintomáticos, praticantes de atividade física, com o objetivo de compará-los e formar um grupo controle. Este grupo foi empregado, também, com a finalidade de estabelecer parâmetros quantitativos em atletas assintomáticos (sem diagnóstico clínico de fratura de estresse), A relação dos pacientes assintomáticos e suas características estão apresentadas na tabela 2, e 
passaremos a referi-los como grupo II. A descrição completa da casuística e resultados do grupo II está apresentada no anexo 3.

Foi obtida previamente a aprovação da comissão de ética e todos os pacientes assinaram o termo de consentimento para o estudo clínico e para a realização dos exames diagnósticos. 
Tabela 1 - Relação de pacientes sintomáticos (grupo I)

\begin{tabular}{|c|c|c|c|c|c|}
\hline Inicias & Idade & Sexo & Lado & Esporte & $\begin{array}{c}\text { Intensidade atividade física } \\
\text { (horas/semana) }\end{array}$ \\
\hline $\mathrm{GHL}$ & 26 & $M$ & ESQ & handebol & 7,0 \\
\hline GMC & 33 & M & ESQ & corrida & 5,5 \\
\hline MSC & 38 & $F$ & ESQ & corrida & 2,5 \\
\hline RW & 22 & $M$ & DIR & triatlo & 2,5 \\
\hline MTP & 26 & $F$ & DIR & corrida & 3,0 \\
\hline JES & 37 & M & DIR & corrida & 5,0 \\
\hline$G Z$ & 23 & M & DIR & basquete & 5,0 \\
\hline CT & 23 & $\mathrm{~F}$ & DIR & corrida & 3,5 \\
\hline CB & 34 & M & DIR & corrida & 4,0 \\
\hline SMB & 28 & $F$ & ESQ & corrida & 5,0 \\
\hline DM & 27 & M & ESQ & corrida & 3,0 \\
\hline JS & 28 & $\mathrm{~F}$ & DIR & saltos & 6,0 \\
\hline AM & 52 & $M$ & ESQ & corrida & 3,0 \\
\hline GL & 25 & M & DIR & handebol & 7,0 \\
\hline $\mathrm{ACM}$ & 28 & $F$ & ESQ & corrida & 4,0 \\
\hline MC & 44 & M & ESQ & corrida & 3,5 \\
\hline PAE & 26 & $M$ & DIR & corrida & 4,0 \\
\hline MLV & 26 & $\mathrm{~F}$ & $E S Q$ & futebol & 3,5 \\
\hline JO & 36 & M & DIR & corrida & 3,5 \\
\hline SND & 26 & M & $E S Q$ & triatlo & 3,5 \\
\hline SB & 56 & $F$ & DIR & corrida & 5,0 \\
\hline Média & 31,62 & & & & 4,24 \\
\hline Desvio padrão & 9,39 & & & & 1,34 \\
\hline Mínimo & 22,00 & & & & 2,50 \\
\hline Máximo & 56,00 & & & & 7,00 \\
\hline
\end{tabular}


Tabela 2 - Relação de pacientes assintomáticos (grupo II)

\begin{tabular}{|c|c|c|c|c|}
\hline Iniciais & Idade & Sexo & Esporte & $\begin{array}{c}\text { Intensidade atividade física } \\
\text { (horas/semana) }\end{array}$ \\
\hline MAT & 29 & $\mathrm{M}$ & corrida & 3,0 \\
\hline WC & 39 & M & corrida & 3,5 \\
\hline $\mathrm{RI}$ & 26 & M & corrida & 4,0 \\
\hline LFT & 32 & M & corrida & 3,5 \\
\hline PM & 28 & $\mathrm{~F}$ & corrida & 5,0 \\
\hline $\mathrm{ACC}$ & 28 & $\mathrm{~F}$ & triatlo & 2,5 \\
\hline CDP & 26 & $\mathrm{~F}$ & triatlo & 5,5 \\
\hline $\mathrm{KM}$ & 27 & $F$ & corrida & 3,0 \\
\hline FB & 32 & M & corrida & 3,5 \\
\hline HNM & 31 & M & corrida & 5,5 \\
\hline Média & 29,80 & & & 3,90 \\
\hline Desvio padrão & 3,94 & & & 1,07 \\
\hline Mínimo & 26,00 & & & 2,50 \\
\hline Máximo & 39,00 & & & 5,50 \\
\hline
\end{tabular}

Abreviaturas utilizadas nas Tabelas 1 e 2:

DIR: direito

ESQ: esquerdo

M: masculino

$\mathrm{F}$ : feminino 


\subsection{Metodologia}

\subsubsection{Avaliação Clínica}

Os pacientes foram submetidos à anamnese e ao exame físico conforme protocolo pré-estabelecido (Anexo 1).

$\mathrm{Na}$ anamnese identificaram-se o esporte, o número de horas de prática e a quilometragem semanal, a localização da dor e a data de início dos sintomas, a intensidade da dor e sua correlação com o período de aparecimento e, ainda, as alterações menstruais nas mulheres.

No exame físico valorizaram-se inspeção e palpação do local doloroso, alterações anatômicas dos pés e joelhos, encurtamentos musculares e discrepâncias de membros inferiores.

\subsubsection{Ressonância Magnética}

Todos os exames de ressonância magnética foram realizados em aparelho de 1.0 Tesla da empresa Philips, modelo NT10.

Foram realizadas seqüências TSE (turbo spin eco) T1 e T2 com supressão de gordura em planos coronais e axiais, utilizando-se a bobina de joelho.

A espessura de corte foi de $5 \mathrm{~mm}$ e o campo de visão (FOV) variou de $16 \mathrm{~cm}$ nas aquisições axiais a $20 \mathrm{~cm}$ nas aquisições coronais. 
O tempo de Eco (TE) nas seqüências T1 variou de 12 mseg a 16 mseg e nas seqüências T2 com supressão de gordura de 60 a 65 mseg.

O tempo de repetição foi adequado ao número de cortes, variando de 400 a 700 mseg nas sequências T1 e de 1800 mseg a 3500 mseg nas seqüências T2 com supressão de gordura.

\subsubsection{Cintilografia Óssea}

Foi realizada a cintilografia óssea trifásica para diagnóstico e seguimento evolutivo dos pacientes com fratura de estresse em equipamento da marca ADAC, modelo VERTEX.

Imediatamente após a injeção endovenosa de HEDP_99mTc (hydroxy ethylidene diphosphonate marcado com tecnécio-99 metaestável), foram obtidas imagens seqüenciais a cada 2 segundos, durante 1 a 2 minutos, seguidas por imagens estáticas para caracterizar fluxo sangüíneo e eventuais áreas de hiperemia.

A dose do radiofármaco foi calculada multiplicando-se o peso do paciente em $\mathrm{Kg}$ por 11,1 a $14,8 \mathrm{MBq}(0,3$ a $0,4 \mathrm{mCi})$. O paciente foi então orientado a realizar hiper-hidratação e a urinar sempre que necessário.

Cerca de 3 a 4 horas após a administração do radiofármaco, foram obtidas imagens com alta resolução da região acometida e da estrutura contralateral. 
Estas imagens representam o grau de remodelação óssea presente em cada região estudada, mais especificamente, a deposição do agente polifosfatado na matriz óssea.

De forma geral, as imagens de fluxo e as imagens imediatas foram obtidas em matriz $64 \times 64 \times 16$ pixels e as imagens tardias em matriz 256x256x16 pixels com colimador de ultra-alta resolução e baixa energia.

4.2.4. Interpretação dos Resultados dos Métodos de Imagem.

As imagens foram avaliadas por dois radiologistas especializados em ressonância magnética músculo-esquelética (C.H.L., 14 anos de experiência e H.G., 9 anos de experiência) e dois especialistas em medicina nuclear (C.B., 21 anos de experiência e A.G., 12 anos de experiência). Ambos realizaram a leitura de forma independente e duplo-cega, sem conhecimento dos dados clínicos da amostra estudada.

O tempo médio entre a realização da ressonância magnética e a avaliação clínica foi de 4 dias (variando entre 2 e 7 dias), e o tempo médio entre a realização da ressonância magnética e a cintilografia óssea foi de 2 dias (variando até 4 dias).

O exame de ressonância magnética foi considerado positivo para fratura por estresse quando qualquer achado descrito por Fredericsson et al. (1995) foi encontrado, utilizando-se a graduação descrita pelo referido autor e dividida em quatro níveis: 
Grau 1: edema periosteal leve a moderado apenas em imagens pesadas em T2, sem edema medular associado (figuras 1 e 2);

Grau 2: edema periosteal mais intenso assim como edema da medular óssea apenas em imagens pesadas em T2 (figuras 3 e 4);

Grau 3: edema periosteal e medular de moderado a intenso, tanto em T1 quanto em T2 (figuras 5 e 6);

Grau 4: traço de fratura em todas as seqüências, associado a intenso edema medular em T1 e em T2 (figuras 7 e 8). 
Figuras 1 e 2 - Imagens de ressonância magnética em corte transverso, seqüência ponderada em T2 à esquerda, mostrando área de hipersinal no periósteo e, à direita, seqüência ponderada em T1 normal

(Grau 1 de Fredericson)
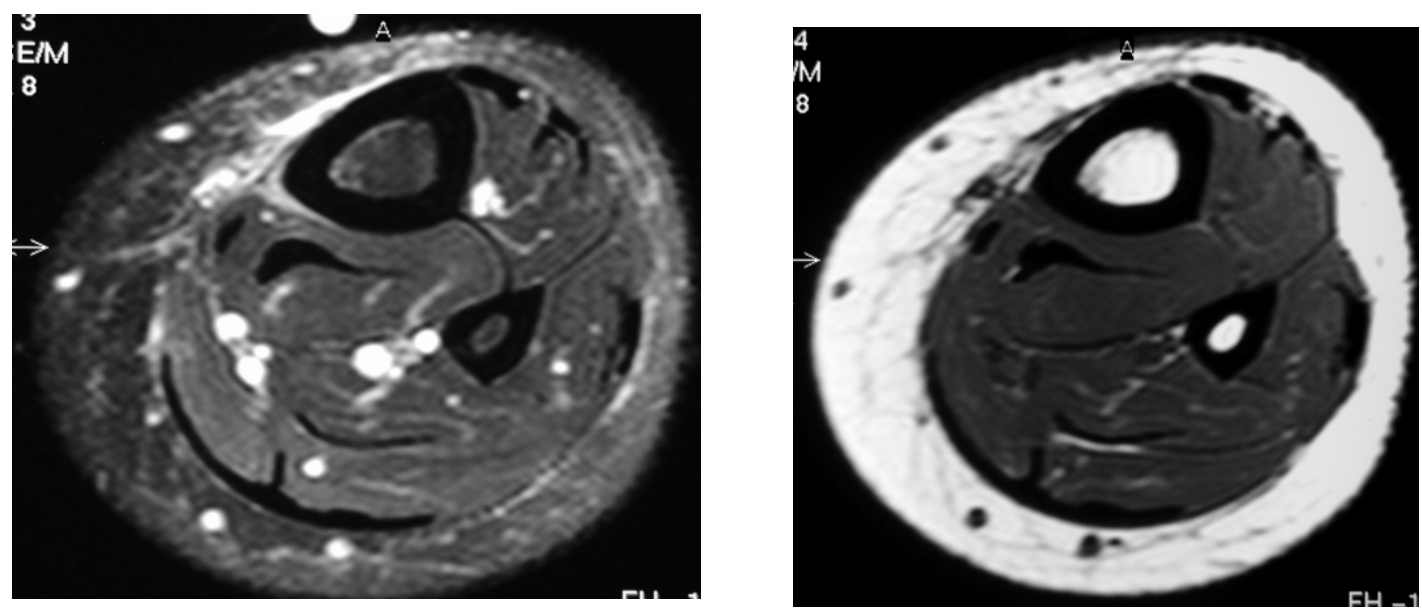

Figuras 3 e 4 - Imagens de ressonância magnética em corte transverso, seqüência ponderada em T2, à esquerda, mostrando área de hipersinal na medular óssea e seqüência ponderada em T1 normal, à direita

(Grau 2 de Fredericson)
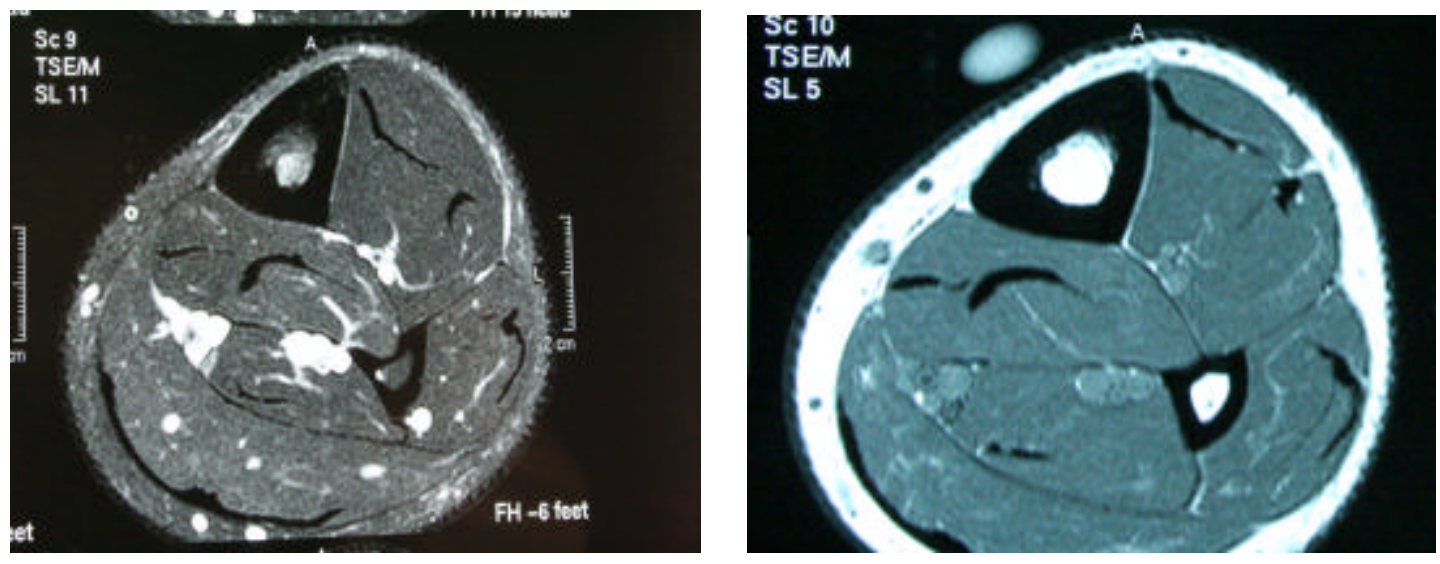
Figuras 5 e 6 - Imagens de ressonância magnética em corte sagital mostrando seqüência ponderada em T2, à esquerda, mostrando hipersinal na medular óssea e ponderada em T1, à direita, mostrando hiposinal na medular óssea (Grau 3 de Fredericson)
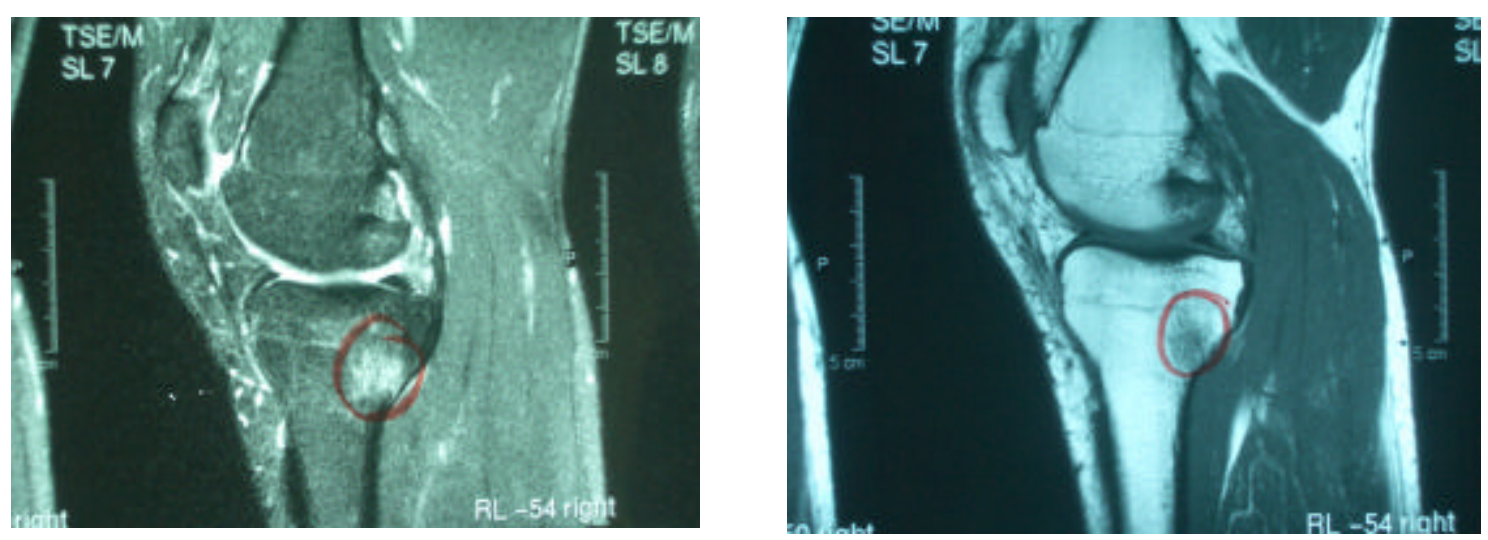

Figuras 7 e 8 - Imagens de ressonância magnética em corte coronal mostrando seqüência ponderada em T2, à esquerda, mostrando hipersinal e traço de fratura e seqüência ponderada em $\mathrm{T} 1$, à direita, mostrando hipossinal na medular óssea (Grau 4 de Fredericson)
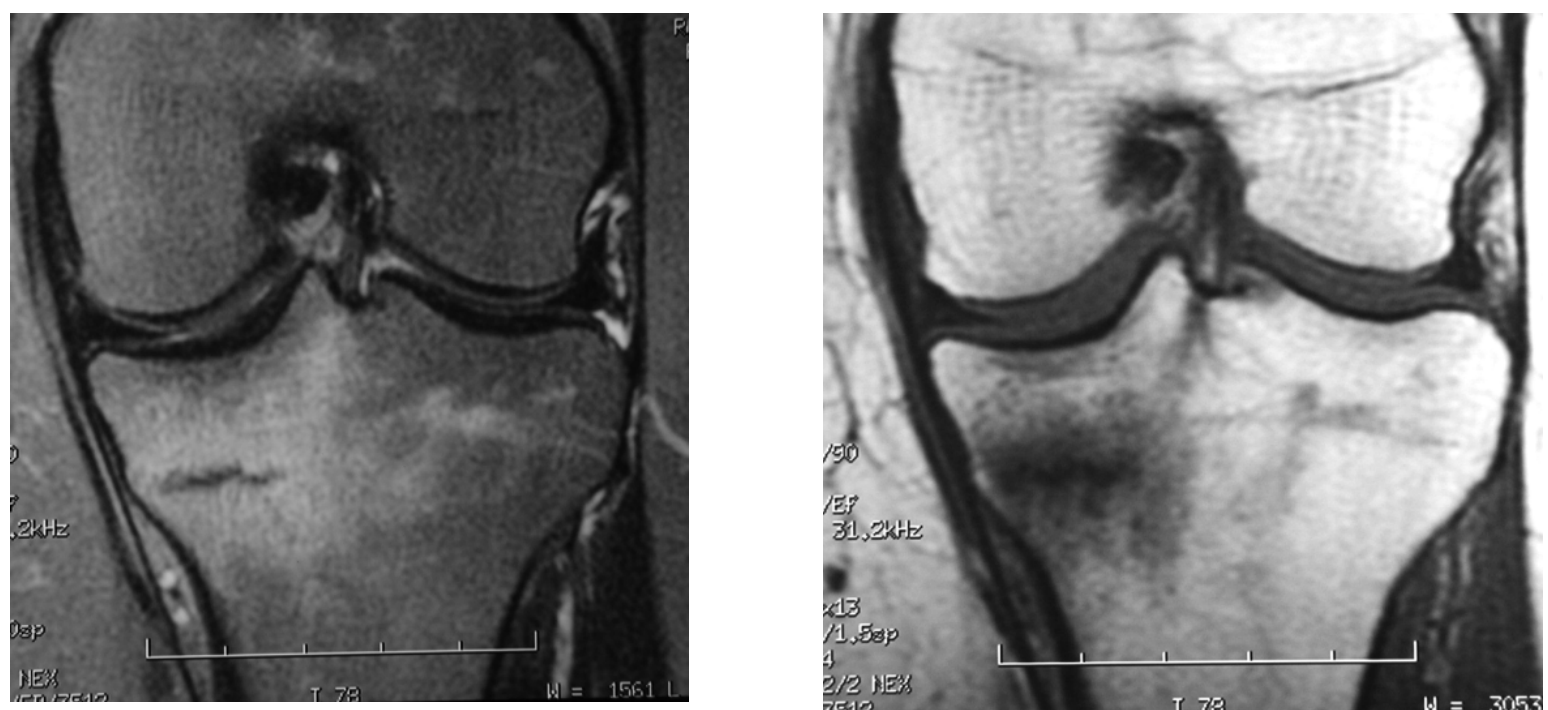
A cintilografia óssea foi considerada positiva, quando apresentava qualquer aumento de captação localizado ou focal, baseando-se no estudo de Zwas et al. (1987). Contudo, a proposta de classificação de comprometimento proposta por este autor não foi empregada neste trabalho, pois testou-se outro método de análise semiquantitativa para predizer o tempo de repouso necessário.

A análise quantitativa foi realizada, desenhando-se uma região de interesse (ROI) no sítio de fratura, registrando-se o número total de contagens ali presente (CTGfst). Seqüencialmente, obtivemos uma região de interesse exatamente do mesmo tamanho, por duplicação, a qual foi alocada sobre a mesma região contra-lateral, anotando-se também o número total de contagens (CTGcl). A relação CTGfst/CTGcl foi, então, calculada e denominada índice de avaliação quantitativa (figura 9):

Figura 9 - Análise quantitativa da cintilografia óssea

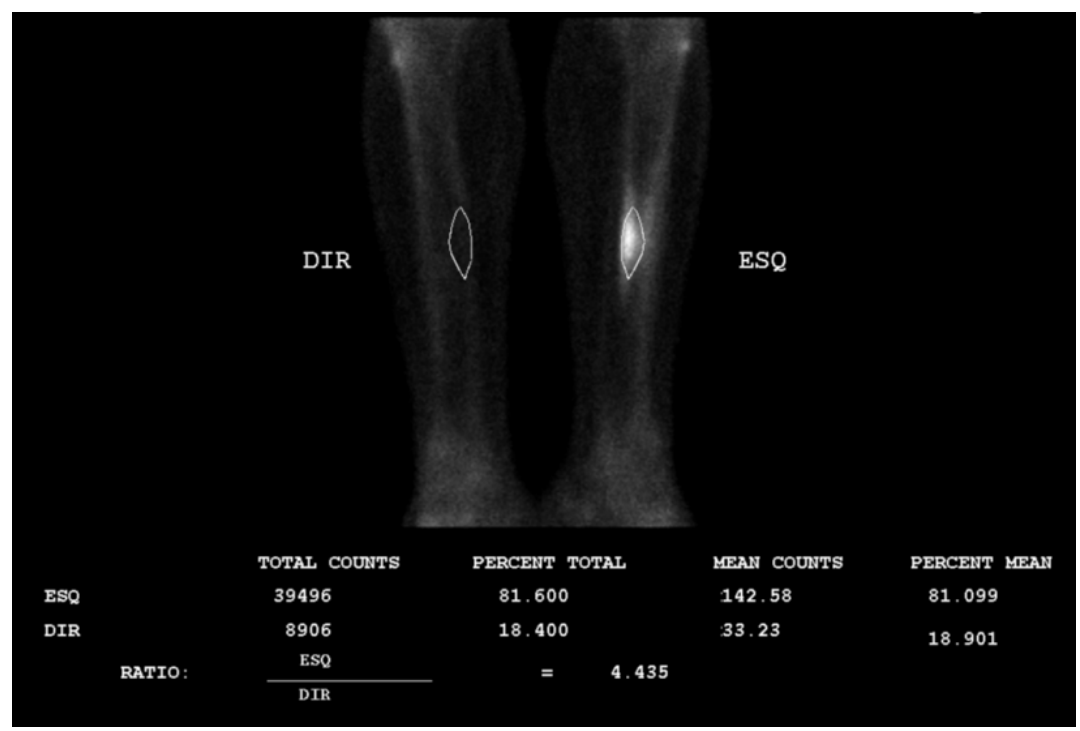


Para avaliar o grau de detectabilidade de fratura de estresse pelos dois métodos, segundo o diagnóstico clínico, usou-se a análise qualitativa visual. A classificação de Fredericson e quantitativa por técnica de ROI na cintilografia foram empregadas para determinar o valor prognóstico na predição do tempo de retorno à prática de atividades esportivas.

\subsubsection{Protocolo de retorno à atividade física:}

Os pacientes foram acompanhados por meio de protocolo de retorno à atividade física pré-estabelecido por Arendt et al. (2003), que determina quatro estágios progressivos:

Fase I: os pacientes foram orientados a retirar carga, se apresentassem dor à deambulação; a imobilizar a perna, se necessário, para alívio dos sintomas e a atividade física foi permitida somente na água (natação ou corrida com flutuador);

Fase II: foram permitidas as atividades sem impacto como bicicleta, elíptico ou caminhada, além do fortalecimento de membros inferiores;

Fase III: corridas foram introduzidas em intervalos de 2 a 3 minutos, em dias alternados, com aumento gradual, e os pacientes foram orientados a correr em esteira durante esta fase;

Fase IV: os pacientes foram liberados para correr em qualquer terreno e reintroduzirem esporte específico também em intervalos graduais de 2 a 3 minutos, em dias alternados. 
Os pacientes foram avaliados semanalmente e orientados a só passarem para a próxima fase do protocolo quando permanecessem assintomáticos por cinco dias.

Se a dor reaparecesse, o paciente retornaria à fase anterior por mais cinco dias, e assim, progressivamente, até a fase quatro de retorno ao esporte específico.

Todos os pacientes foram acompanhados com avaliações semanais durante o período de recuperação, e mensais após o período de retorno à atividade física específica por, no mínimo, seis meses após a fase IV.

\subsection{Análise Estatística}

A análise estatística realizada constou inicialmente da descrição da amostra com respeito às variáveis clínicas analisadas, assim como a descrição dos achados de imagem na análise visual e quantitativa.

$\mathrm{Na}$ comparação dos métodos de ressonância magnética e cintilografia, utilizamos os conceitos de sensibilidade e especificidade, como a seguir:

O teste é positivo e o paciente tem a doença - Verdadeiro Positivo (VP);

O teste é positivo mas o paciente não tem a doença - Falso Positivo (FP);

O teste é negativo e o paciente tem a doença - Falso Negativo (FN) e

O teste é negativo e o paciente não tem a doença - Verdadeiro Negativo (VN). 
Sensibilidade de um teste é definida pela proporção de pessoas com a doença de interesse, que têm o resultado do teste positivo. Indica a certeza para identificar os indivíduos doentes e pode ser calculada por meio da fórmula:

$$
\text { Sensibilidade }=V P / V P+F N
$$

Especificidade de um teste é a proporção de pessoas sem a doença que têm o teste negativo. Indica a certeza para identificar os indivíduos não doentes e pode ser calculada por meio da fórmula:

$$
\text { Especificidade }=\mathrm{VN} / \mathrm{VN}+\mathrm{FP}
$$

Pesquisamos, então, a existência de diferença entre os grupos sintomático e assintomático, em relação à variável hipercaptação.

Utilizamos a análise de variância de um fator para testarmos a hipótese nula de que a média da hipercaptação do grupo sintomático é igual à média da hipercaptação do grupo assintomático.

Passamos a determinar o ponto crítico a partir do qual podemos considerarmos que a hipercaptação indique uma fratura por estresse.

O ponto crítico que a hipercaptação indica como fratura por estresse foi calculado, utilizando a equação a seguir:

$$
\text { Ponto Critico }=\text { média }+z_{\text {? }} \text { desvio padrão }
$$

z = distribuição normal padrão. Média zero e variância 1 
A comparação entre hipercaptação na cintilografia óssea e a classificação de Fredericson et al. (1995) foi testada por meio da hipótese nula de que os grupos teriam todos a mesma média de hipercaptação na análise de variância, determinando o agrupamento dos indivíduos analisados que mais se assemelhasse ao método de Fredericson.

Na próxima etapa estabelecemos uma relação entre a intensidade da hipercaptação pela análise quantitativa e o tempo de recuperação dos pacientes.

Utilizamos um modelo de regressão linear múltiplo, no qual o tempo de recuperação é a variável dependente e a hipercaptação, a idade, o lado da lesão e o sexo são as variáveis independentes.

Foram utilizados somente os 21 pacientes do grupo I para o modelo de regressão linear múltiplo:

$$
Y=B \cdot X+e
$$

Y - Variáveis dependentes. No caso, tempo de recuperação do paciente B - Vetor de parâmetros

X - Variáveis independentes: hipercaptação e idade.

? - Vetor de resíduos iid $\mathrm{N}\left(0, ?^{2}\right)$. Independentes identicamente distribuídos.

Utilizamos o método BACKWARD de seleção de variáveis com nível de significância, para que as variáveis continuassem no modelo de $10 \%$. 


\section{RESULTADOS}

\subsection{Distribuição e análise de parâmetros clínicos nos grupos I e II}

A média de horas de treino semanal foi de 4,24 horas (variando entre 2,5 a 7 horas) no grupo I e de 3,90 horas (variando entre 2,5 a 5,5 horas) no grupo II.

A distribuição dos pacientes do grupo I e II, de acordo com o tipo de esporte, encontra-se no gráfico 1.

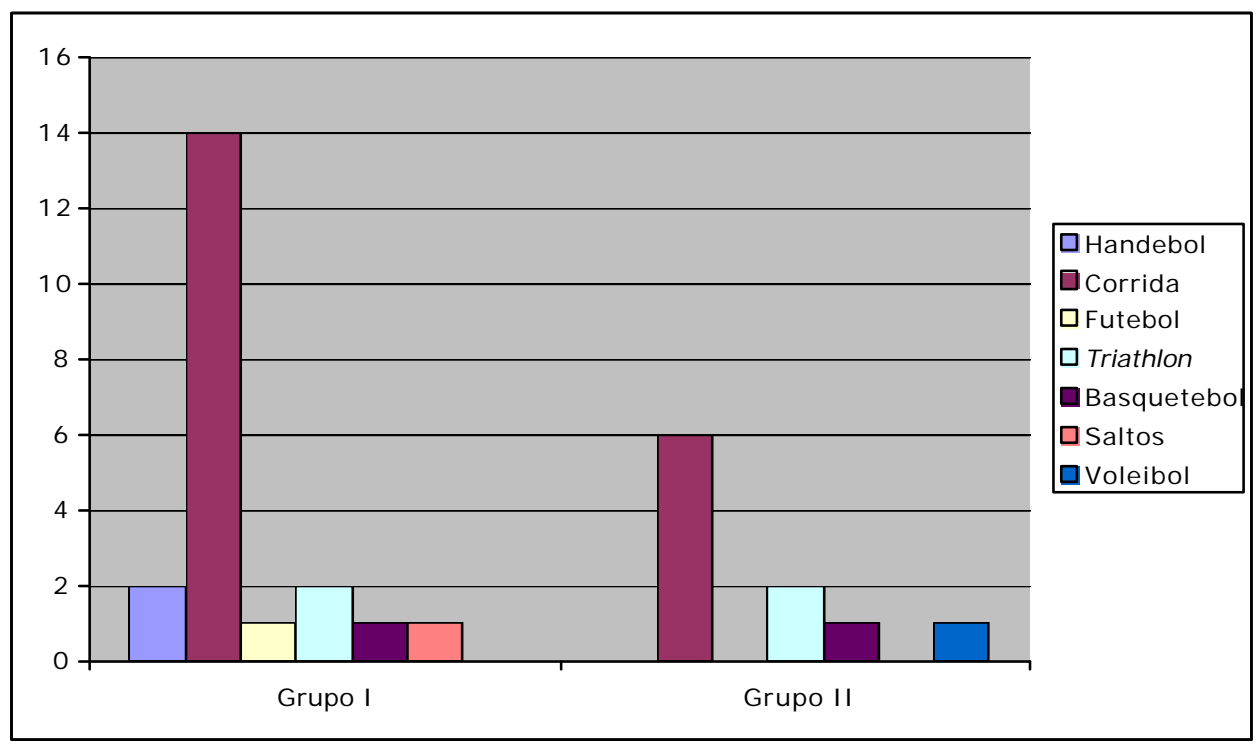

Gráfico 1 - Distribuição dos pacientes do grupo I, de acordo com o tipo de esporte praticado 
Em relação à localização da sintomatologia dolorosa, observoutse predomínio de localização no terço médio da tíbia. Os pacientes do grupo I apresentaram dor no terço proximal da tíbia em 2 casos $(23,8 \%)$, terço médio em 18 casos $(71,4 \%)$ e no terço distal em 1 caso $(4,8 \%)$, como pode ser demonstrado no gráfico 2.

Gráfico 2 - distribuição dos pacientes do grupo I, de acordo com a localização da dor

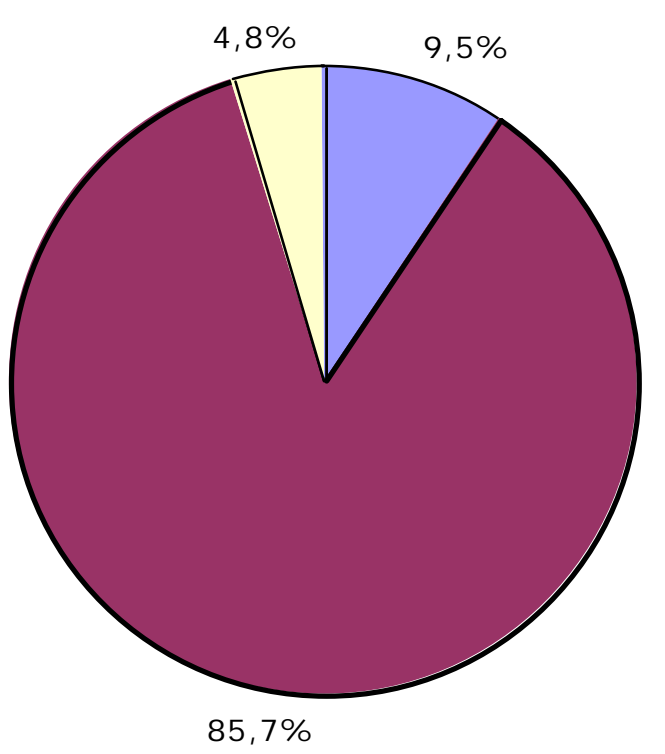


5.2. Avaliação dos resultados cintilográficos pela análise visual nos grupos I e II

O grupo I apresentou alterações cintilográficas em 21 pacientes (100\%), e o grupo 2 apresentou alterações cintilográficas em 4 pacientes (40\%), conforme demonstrado no gráfico 4.

Gráfico 3 - Distribuição dos pacientes dos grupos I e II, com relação à análise visual na cintilografia óssea

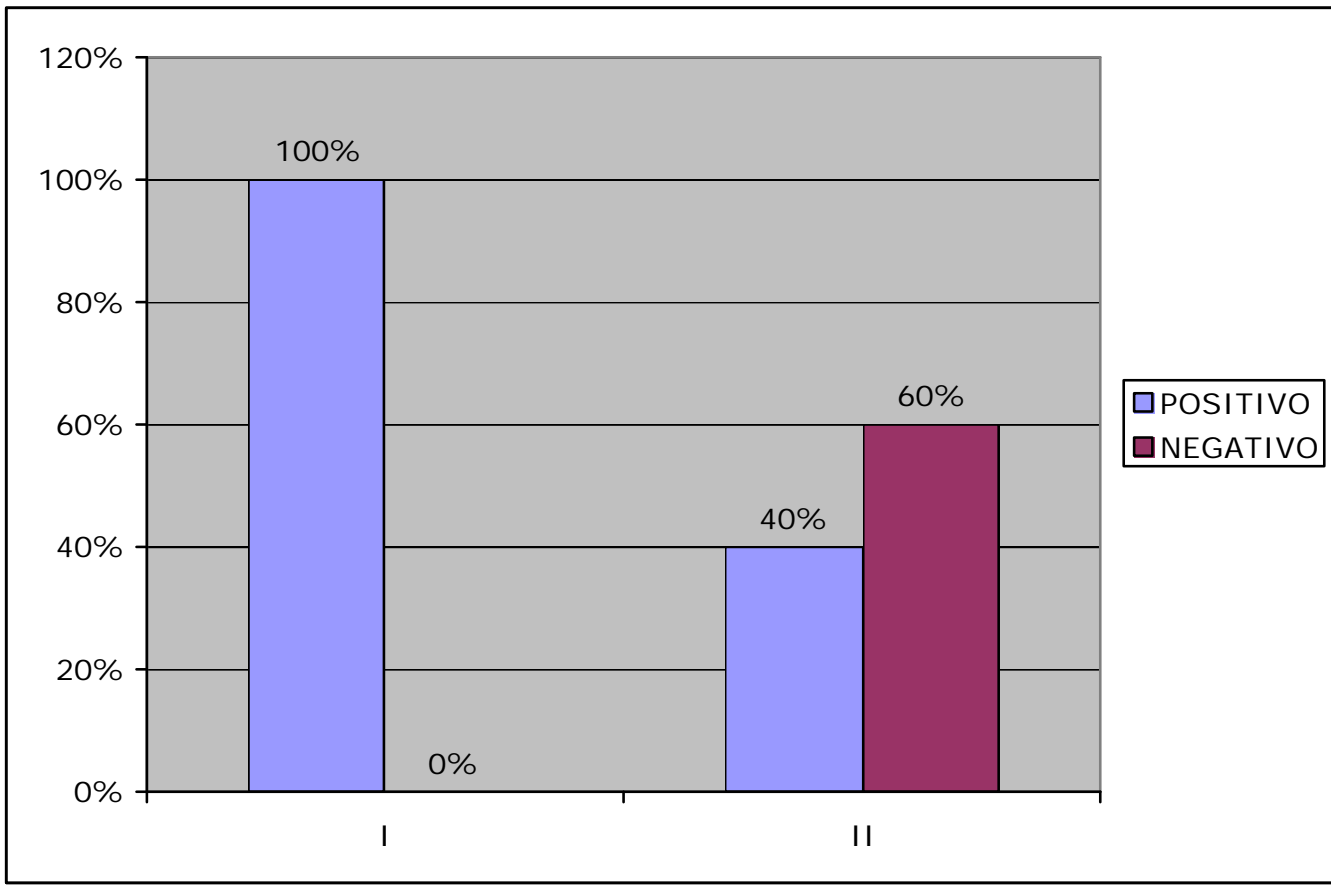




\subsection{Avaliação dos resultados de ressonância magnética pela análise} visual nos grupos I e II

O grupo I apresentou alterações na ressonância magnética em 21 pacientes (100\%), e o grupo 2 apresentou alterações na ressonância magnética em 4 pacientes (40\%), conforme observamos no gráfico 5 . Contudo, dos quatro pacientes do grupo II com ressonância magnética alterada, três mostravam anormalidades também à cintilografia.

Gráfico 4 - Distribuição dos pacientes dos grupos I e II, com relação à análise visual na ressonância magnética

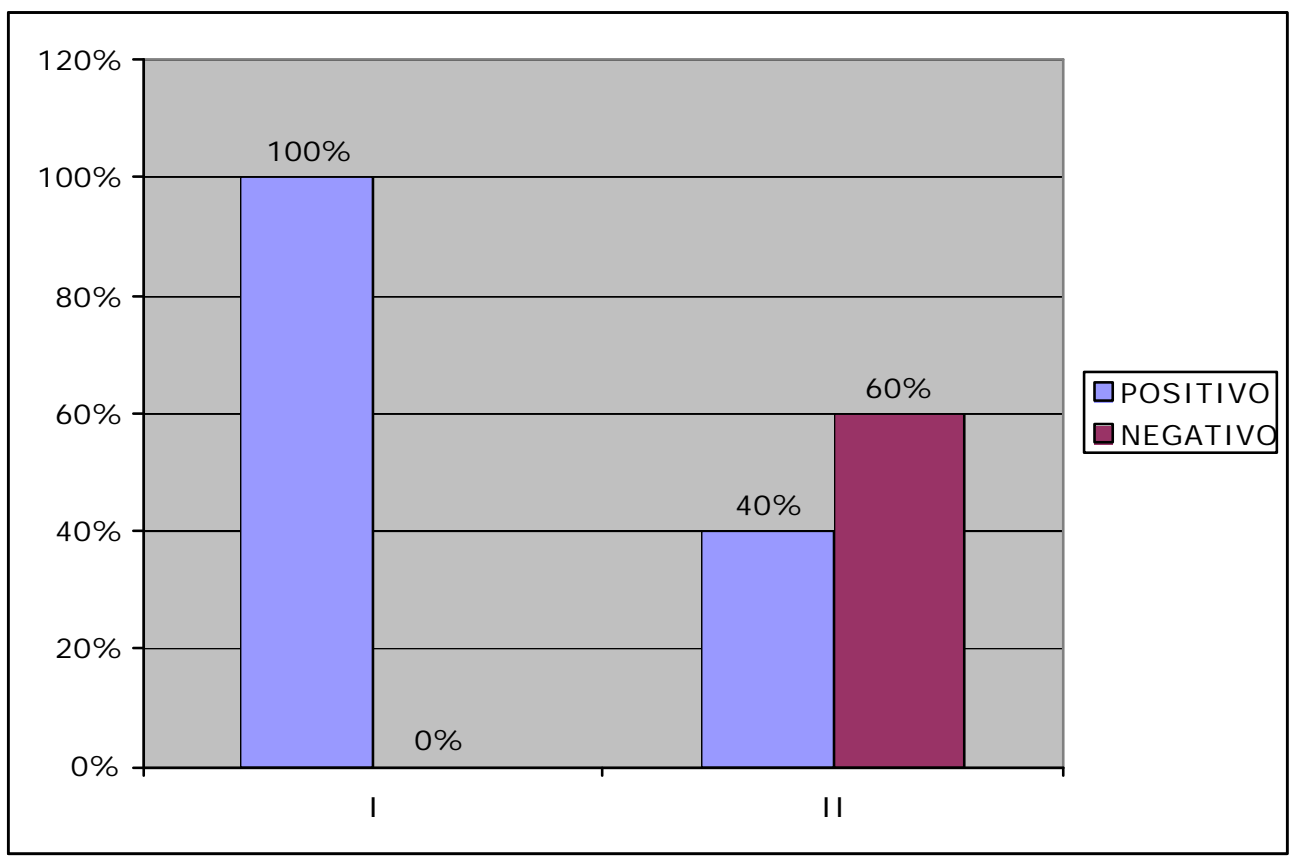


5.4. Comparação da análise visual pela cintilografia óssea e ressonância magnética nos grupos I e II - detecção da sensibilidade e especificidade

O grupo I apresentou alterações cintilográficas em 21 pacientes (100\%), enquanto o grupo II apresentou alterações cintilográficas em 4 pacientes (40\%), conforme observamos na tabela 3 .

Tabela 3 - Distribuição do resultado da cintilografia óssea nos pacientes dos grupos I e II

\begin{tabular}{ccccc}
\hline & & \multicolumn{3}{c}{ Fratura de estresse } \\
\hline & & Presente & Ausente & Total \\
Cintilografia & Positiva & 21 & 4 & 25 \\
& Negativa & 0 & 6 & 6 \\
& & 21 & 10 & 31 \\
\hline
\end{tabular}

Sensibilidad $00,00^{\circ}$

Especificidade 60,00 \% 
O grupo I apresentou alterações na ressonância magnética em 21 pacientes (100\%), enquanto o grupo II apresentou alterações na ressonância magnética em 4 pacientes (40\%), conforme a tabela 4.

Tabela 4 - Distribuição do resultado da ressonância magnética nos pacientes dos grupos I e II

\begin{tabular}{lcccc}
\hline & \multicolumn{4}{c}{ Fratura de estresse } \\
\hline & & Presente & Ausente & \\
Ressonância Magnética & Positiva & 21 & 4 & 25 \\
& Negativa & 0 & 6 & 6 \\
& & 21 & 10 & 31 \\
\hline
\end{tabular}

$\begin{array}{rr}\text { Sensibilidade } & 100,00 \% \\ \text { Especificidade } & 60,00 \%\end{array}$




\subsection{Avaliação dos resultados cintilográficos pela análise quantitativa}

Os índices quantitativos (baseados nos valores obtidos com 0 delineamento das regiões de interesse) foram analisados em cada um dos grupos com o objetivo de avaliar a distribuição média dos valores.

A tabela 5 mostra o número de pacientes nos grupos I e II, a soma, a média e o desvio padrão dos índices de captação encontrados na cintilografia óssea nos grupos I e II, assim como apresenta a base de cálculo para análise de variância entre os grupos.

Tabela 5 - Apresentação dos dados para análise estatística de variância nos grupos I e II

Anova: "single factor"

\begin{tabular}{ccccc}
\hline Grupos & $\boldsymbol{n}$ & Soma & Média & Desvio padrão \\
\hline I & 21 & 53,40 & 2,54 & 0,77 \\
II & 10 & 10,52 & 1,05 & 0,11 \\
\hline
\end{tabular}

\begin{tabular}{ccccccc}
\hline Fonte de Variação & SS & $\boldsymbol{d f}$ & $\boldsymbol{M S}$ & $\boldsymbol{F}$ & $\boldsymbol{P}$-value & $\boldsymbol{F}$ crit \\
\hline Entre grupos & 15,057 & 1 & 15,057 & 28,108 & 0,00001 & 4,183 \\
Dentro dos grupos & 15,535 & 29 & 0,536 & & & \\
& & & & & & \\
Total & 30,591 & 30 & & & & \\
\hline
\end{tabular}

Abreviaturas:

SS: "sum square" (soma de quadrados)

dF: "degrees of freedom" (graus de liberdade)

MS: "mean square" (média quadrática)

P-value: valor de $p$ n: número de pacientes

$F: F$

Fcrit: F crítico 


\subsection{Estimativa do valor de captação cintilográfica óssea que melhor se} asssocia à probabilidade de fratura de estresse.

Com base na média e desvio padrão obtidos do índice quantitativo na cintilografia óssea do grupo II (respectivamente 1,05 e 0,11), foram calculadas as probabilidades e os pontos críticos expressos na tabela 6 , a partir da fórmula:

\section{Ponto crítico $=$ média $+\mathbf{z}$. desvio padrão}

Tabela 6 - Apresentação da variável z e a probabilidade de uma fratura de estresse de acordo com o índice de captação obtido na cintilografia óssea

\begin{tabular}{ccc}
\hline Variável z & $\begin{array}{c}\text { Probabilidade de } \\
\text { fratura de estresse }\end{array}$ & Ponto crítico \\
\hline 1,64 & $90 \%$ & 1,23 \\
2,00 & $95 \%$ & 1,27 \\
2,33 & $99 \%$ & 1,30 \\
\hline
\end{tabular}




\subsection{Avaliação dos resultados de ressonância magnética pela análise de} Fredericson nos grupos I e II

O grupo I apresentou alterações na ressonância magnética em todos os pacientes, sendo quatro com grau 1 , nove com grau 2 , seis com grau 3 e dois com grau 4.

O grupo II apresentou quatro pacientes com alterações na ressonância magnética, todos com grau 1, como observado no gráfico 6 .

Gráfico 5 - Distribuição dos pacientes dos grupos I e II, de acordo com a classificação visual de Fredericson et al. (1995) de ressonância magnética

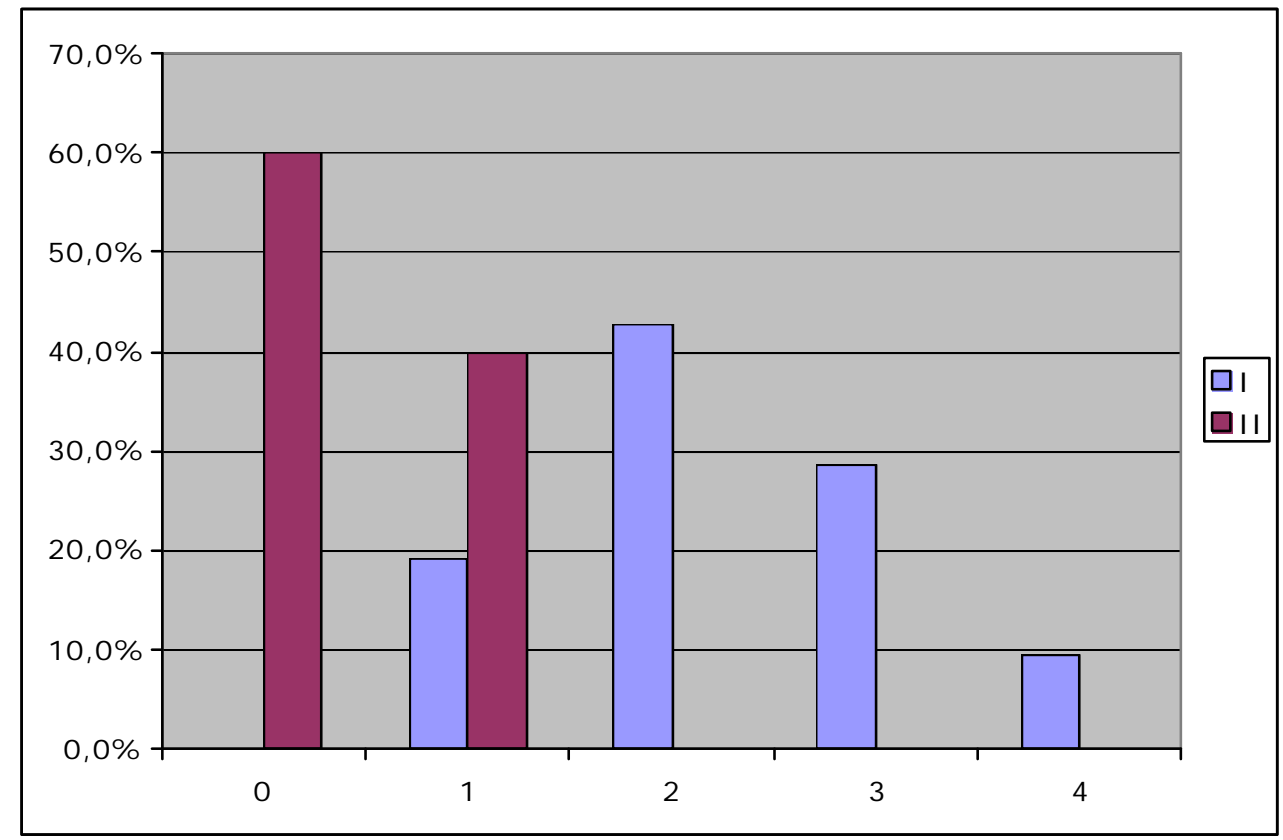


5.8. Distribuição dos resultados cintilográficos e de ressonância magnética do grupo I, segundo análise quantitativa e classificação de Fredericson

Do total de pacientes do grupo I, quatro pacientes $(19,0 \%)$ encontraram-se no grau 1 de Fredericson, nove pacientes $(42,8 \%)$ encontraram-se no grau 2 , seis pacientes $(28,6 \%)$ encontraram-se no grau 3 e apenas dois pacientes (9,5\%) encontraram-se no grau 4, conforme distribuição no gráfico 7 .

Gráfico 6 - Distribuição dos pacientes do grupo I de acordo com a classificação de Fredericson et al. (1995) e índice de hipercaptação na cintilografia óssea

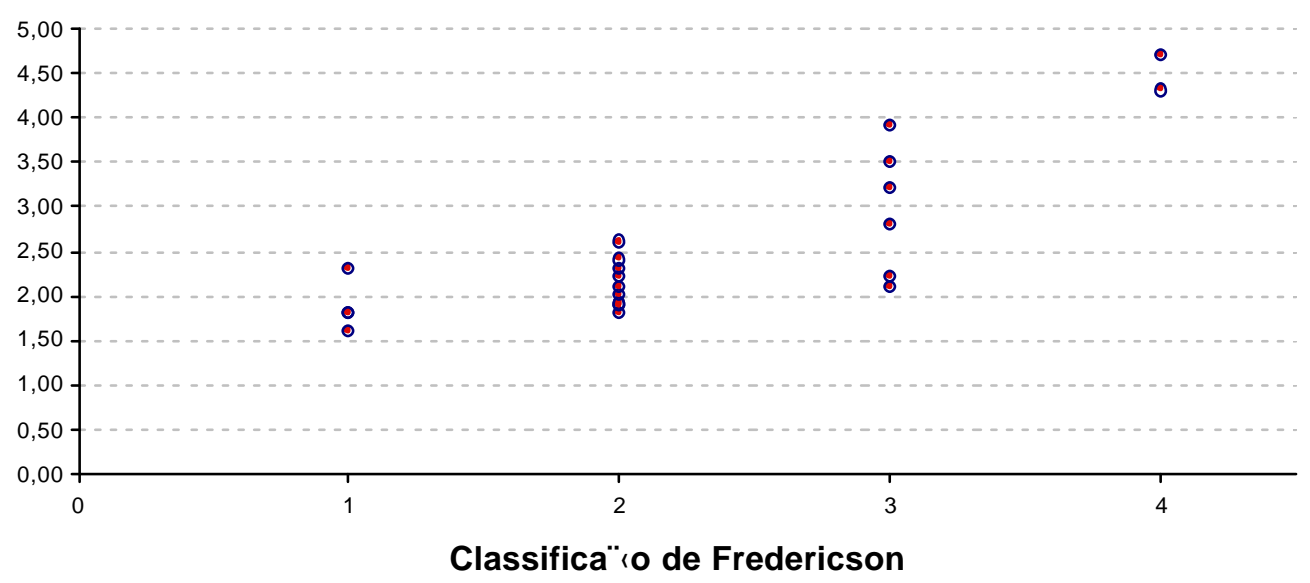


Com o intuito de avaliar se os subgrupos obtidos pelos diferentes índices quantitativos são estatisticamente diferentes entre si, aplicou-se a análise de variância, testando as seguintes hipóteses e conforme demonstrado da tabela 7:

Hipótese H0: $\quad$ MedHiper $1=$ MedHiper $2=$ MedHiper $3=$ MedHiper 4

Hipótese HA: $\quad$ MedHiper 1 = MedHiper $2<$ MedHiper $3=$ MedHiper 4

A hipótese nula foi rejeitada no nivel de $1 \%$

Tabela 7- Apresentação dos dados para análise estatística de variância nos grupos I, II, III e IV de Fredericson

\section{Anova: "single factor}

\begin{tabular}{ccccc}
\hline Grupos & $\boldsymbol{n}$ & Soma & Média & Desvio padrão \\
\hline I e II & 13 & 26,7 & 2,054 & 0,084 \\
III e IV & 8 & 26,7 & 3,338 & 0,894 \\
\hline
\end{tabular}

\begin{tabular}{ccccccc}
\hline Fonte de Variação & SS & $\boldsymbol{d f}$ & $\boldsymbol{M S}$ & $\boldsymbol{F}$ & $\boldsymbol{P}$-value & $\boldsymbol{F}$ crit \\
\hline Entre grupos & 8,160 & 1 & 8,160 & 21,324 & 0,00002 & 4,381 \\
Dentro dos grupos & 7,271 & 19 & 0,383 & & & \\
& & & & & & \\
Total & 15,431 & 20 & & & & \\
\hline
\end{tabular}

Abreviaturas:

SS: "sum square" (soma de quadrados)

dF: "degrees of freedom (graus de liberdade)

MS: "mean square" (média quadrática)

P-value: valor de $p$ $\mathrm{n}$ : número de pacientes

$F: F$

Fcrit: F crítico 
Conforme observado acima, pode-se separar a presente amostra em três grupos, associando-se os resultados quantitativos da cintilografia e a classificação de Fredericson pela ressonância magnética, ou seja, subgrupo sem alterações, subgrupo com anormalidades discretas e subgrupo com alterações acentuadas. Portanto, pelos resultados obtidos acima, e considerando o ponto crítico estabelecido na tabela 6 , definiu-se a seguinte classificação, conforme o índice quantitativo obtido na cintilografia óssea (tabela 8).

Tabela 8 - Probabilidade estimada de presença de fratura de estresse pelo índice quantitativo obtido na cintilografia óssea

\begin{tabular}{ccc}
\hline Hipercaptação & Fredericson & Fratura por estresse \\
\hline$<1,30$ & 0 & Ausente \\
$>1,30 ;<=2,5$ & I e II & Leve \\
$>2,5$ & III e IV & Importante \\
\hline
\end{tabular}




\subsection{Distribuição do tempo de recuperação de acordo com o índice de} captação obtido pela cintilografia óssea

O gráfico 8 relaciona o tempo de recuperação encontrado com o índice de captação obtido na amostra populacional do grupo I, com intervalo de confiança. Observou-se correlação entre as duas variáveis com valores de $R=0,63$ e $p<0,001$.

Gráfico 7 - Distribuição dos pacientes de acordo com o tempo de recuperação e o índice de hipercaptação encontrado na cintilografia óssea

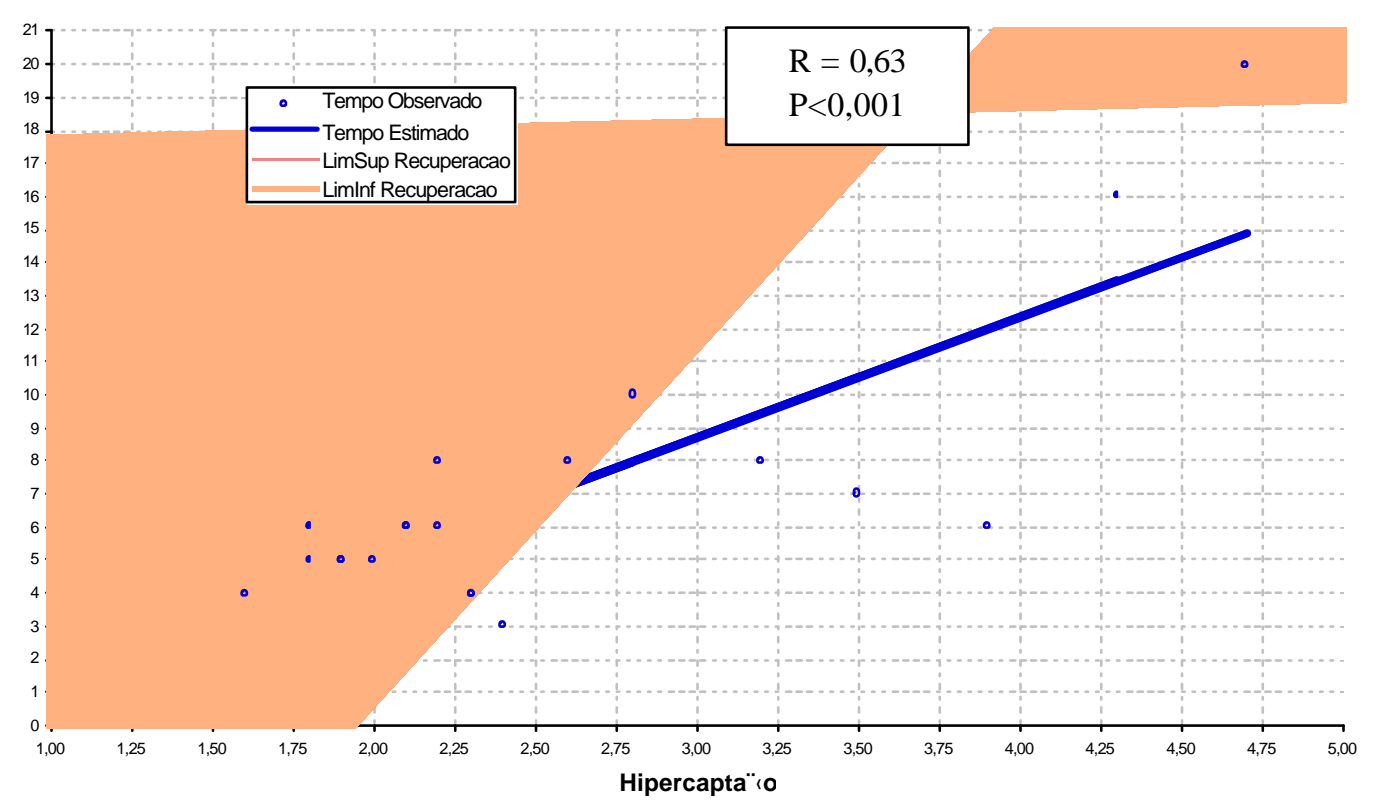


5.10. Estimativa do tempo de recuperação, conforme 0 índice quantitativo obtido pela cintilografia óssea

Baseando-se no gráfico 8, chega-se a uma equação de regressão com o objetivo de determinar o tempo estimado de repouso ou recuperação, conforme o índice de captação observado à cintilografia óssea.

A equação obtida é apresentada pela seguinte fórmula:

Tempo de recuperação (semanas) $=-2,24+3,65$. índice de captação 


\section{DISCUSSÃO}

A fratura por estresse é patologia intrigante pois acomete o osso de forma não traumática e, muitas vezes, afasta o paciente de sua atividade esportiva por longos períodos de recuperação.

Em estudo interessante, Stanitski et al. (1978) descrevem que a fratura de estresse só é encontrada em seres humanos, cachorros e cavalos de corrida, organismos submetidos a treinos, objetivando o máximo de rendimento em atividade específica.

A fratura de estresse é patologia relacionada a pacientes fisicamente ativos e a primeira descrição vem antes dos métodos de imagem, quando Breithaupt, em 1855, descreve as dores nos pés edematosos de recrutas submetidos ao treinamento militar (apud Stanitski et al., 1978).

A partir da década de 1950 se iniciam os estudos correlacionando a patologia a atletas das mais diversas modalidades na forma de descrição de casos (Hartley, 1942; Burrows, 1956; Devas, 1956).

Os estudos epidemiológicos apontam para a prevalência da patologia em atletas de esportes de impactos repetitivos (corredores, saltadores, bailarinas), sendo responsável por 10\% das lesões deste grupo (Bennell et al., 1996a).

A tíbia é apontada pela literatura como o sítio mais freqüente de acometimento da patologia, com uma incidência média de $50 \%$ dos casos de fraturas por estresse (Orava, 1980; Rettig et al, 1988). 
Os estudos de imagem, inicialmente limitados à radiografia simples, pouco contribuíram para o entendimento da patologia (Savoca, 1971).

Com o advento da cintilografia óssea e da ressonância magnética, puderam ser observadas valiosas informações sobre a anatomia e metabolismo ósseo nos pacientes com fraturas por estresse (Roub et al., 1979; Lee e Yao, 1988).

A cintilografia óssea é o exame que aponta precocemente qualquer alteração indicativa de aumento do grau de remodelação óssea (atividade osteoblástica) e apresenta grande sensibilidade no diagnóstico complementar da patologia (Prather et al., 1977). Além disso, a cintilografia óssea, por avaliar precocemente a alteração do metabolismo ósseo, pode mapear áreas assintomáticas que possam vir a se transformar em fraturas por estresse no futuro (Daffner et al., 1982).

Este aumento da atividade metabólica óssea não raramente precede alterações estruturais ou de densidade radiológica comumente observadas à radiografia e mesmo à tomografia computadorizada.

A ressonância magnética pode trazer valiosas informações da anatomia óssea e de partes moles ao redor do sítio de fratura e, com isso, contribuir para o diagnóstico diferencial (Ishibashi et al., 2002).

A ressonância também tem sido descrita como método extremamente sensível, pois a mesma permite detectar alterações precoces de sinal no nível da medular óssea, o que pode indicar algum grau de estresse ou fadiga óssea em evolução (Ishibashi et al., 2002; Kiuru et al., 2002). 
Analisando nossos pacientes com fraturas por estresse, identificamos período de recuperação muito variável (de poucas semanas a meses) e fomos buscar, na literatura, dados que explicassem este achado.

A classificação cintilográfica proposta por Zwas et al. (1987) faz relação com tempo de afastamento de atividades de impacto, considerando a extensão da hipercaptação na cintilografia óssea sem avaliar sua intensidade.

O estudo de Fredericson et al. (1995) classifica as fraturas de estresse de tíbia por meio de ressonância magnética e associa o tempo de recuperação a quatro graus de acometimento ósseo, tornando-se, hoje, valioso instrumento para avaliação do prognóstico nos casos de fraturas por estresse; porém, não encontra correlação entre a classificação proposta e a utilizada por Zwas et al. (1987), ao mesmo tempo que não valida seus resultados com estudos prospectivos randomizados e duplos-cegos.

Apesar do número crescente de estudos neste campo, há poucos trabalhos que buscam um índice ou classificação para orientar o melhor tratamento e o tempo mínimo de afastamento de um atleta das atividades esportivas.

A proposta do presente estudo clínico-radiológico foi associar as características clínicas com os achados de métodos de imagem que avaliam alterações anatômicas (ressonância magnética) e metabólicas (cintilografia óssea), acompanhando estes pacientes até o momento de seu retorno à atividade esportiva, com o objetivo final e principal de encontrar indicadores 
confiáveis que permitam o retorno dos atletas às atividades esportivas com mínimo período de recuperação necessário.

A fratura por estresse da tíbia tem formas de apresentação distintas e, desde cedo, encontramos na literatura descrições destas variações.

A fratura do córtex anterior da tíbia, inicialmente relatada por Burrows (1956), apresenta pior prognóstico em termos de tempo de recuperação (cerca de 3 a 6 meses) e complicações como retardo de consolidação e pseudo-artrose foram descritas por Rettig et al. (1988).

Outra forma de apresentação encontrada é a fratura longitudinal do terço distal, inicialmente descrita por Devas (1960) e analisadas radiologicamente por Shearman et al. (1998) e Pozderac (2002), fraturas de bom prognóstico, relacionadas a bailarinas e saltadores.

A forma de apresentação mais freqüente é a encontrada no terço médio-distal, que se inicia no córtex póstero-medial e avança em direção posterior e superior.

São descritos dois mecanismos que podem explicar o aparecimento das fraturas por estresse na tíbia: o muscular e o de impacto.

A fisiopatologia muscular aparentemente tem relação com contrações musculares ritmadas, em particular do músculo sóleo, associada à tibialgia (ou "shin splint") e de ocorrência maior nos pacientes com grande mobilidade da articulação subtalar.

Em interessante estudo sobre aspectos anatômicos e biomecânicos, Michael e Holder (1985) encontram relação entre a fáscia do músculo sóleo diretamente envolvida na produção de estresse no terço médio da tíbia, em 
especial quando o tornozelo encontra-se em pronação (Vitasalo e Kvist, 1983).

A fisiopatologia por impacto fundamenta-se na Lei de Wolf ("A área sobre a qual se aplica uma carga se modifica por processo de remodelação"), o que explica a maior incidência da patologia nos ossos de carga dos membros inferiores, em especial quando submetidos ao aumento repentino das cargas de treinos (Boden et al., 2001).

Nas fraturas por estresse há um desequilíbrio entre a deposição e a absorção óssea no local da fratura, em decorrência do treinamento excessivo (Boden et al., 2001).

Realizamos extensa revisão da literatura no que diz respeito aos fatores predisponentes, uma vez que o entendimento da patologia e dos elementos envolvidos no tempo de recuperação do paciente é multifatorial e deve ser compreendido.

Os fatores predisponentes podem ser divididos em intrínsecos (inerentes ao indivíduo) e extrínsecos (decorrentes do meio externo).

Como fatores extrínsecos encontramos principalmente o erro do treinamento e o uso de calçados gastos ou inadequados.

A literatura aponta uma progressão de treinos de $10 \%$ na semana, troca de tênis no máximo a cada 500 milhas e máxima quilometragem semanal de 45 milhas como medidas preventivas para o aparecimento de fraturas por estresse (Ballas et al., 1997).

Aparentemente as fraturas por estresse desenvolvem-se após ciclos de três semanas de treinamento. 
Em estudo correlacionando aspectos biomecânicos da resposta do osso ao treinamento, Scully e Besterman (1982) encontram aumento da incidência das fraturas por estresse na terceira semana dos treinamentos, e associam este período à maior remodelação óssea decorrente do estresse. Estes autores propõem eliminação de treinos de impacto nessa semana e observam diminuição da incidência de lesões no grupo submetido a esta variação de treinamento $(1,6 \%)$, quando comparado com o grupo de treinamento convencional $(4,8 \%)$, sem perda do rendimento após a realização final do teste físico.

Em 1990, Burr et al. no estudo experimental em coelhos, induzem estresse ósseo e avaliam as reações semanalmente; encontram a maior remodelação entre a terceira e a sexta semanas, confirmando os achados acima.

Vários fatores intrínsecos anatômicos e inerentes ao paciente são estudados na literatura e apontados como de risco ou predisponentes para fraturas de estresse.

A espessura da tíbia (as tíbias mais estreitas são propensas à patologia) é fator que encontra respaldo em Crossley et al. (1999), quando analisada do ponto de vista ósseo, e em Bennel et al. (1996b), que aponta como fator de risco a circunferência da panturrilha menor que $32,2 \mathrm{~cm}$ nas mulheres.

Maior angulação de rotação externa dos quadris (quanto maior a angulação, maior a probabilidade da patologia) é outro fator descrito por Giladi et al. (1991). 
Nas mulheres, a idade da menarca (maior que 14 anos) e alterações menstruais são fatores de risco para o desenvolvimento de fraturas de estresse (Barrow e Saha, 1988; Korpelainen et al., 2001; Shaffer et al., 2005).

Monteleone (1995) aponta como fatores de risco o sexo, idade e raça, sendo a patologia mais incidente nas mulheres, pacientes de mais idade e na raça branca. Embora em nossa casuística não houvesse diferenças em relação à idade, observou-se predominância discreta do sexo masculino nos dois grupos estudados.

Matheson et al. (1987) correlaciona a presença de pés planos à fratura de estresse na tíbia e fíbula, e o pé cavo à presença de fratura de estresse nos pés e no fêmur.

A maior amplitude de movimentos da articulação subtalar é apontada na literatura como importante fator predisponente, em especial para as fraturas do terço médio, associadas à síndrome de estresse tibial (Mubarak et al., 1982; Vitasalo e Kvist, 1983; Michael e Holder, 1985).

Outros fatores intrínsecos testados na literatura tais como densidade mineral óssea, capacidade aeróbica, força de membros inferiores, composição corporal e análise biomecânica de interação com plataforma de força não encontram relação positiva com a patologia.

Quando realizamos diagnóstico clínico de uma fratura de estresse, podemos lançar mão de métodos de imagem para sua confirmação, estabelecer o diagnóstico diferencial e complementar o entendimento das áreas vizinhas e do grau de acometimento ósseo. 
A radiografia simples se mostra pouco eficiente nos casos de fratura de estresse, por mostrar alterações somente em fase tardia da patologia e por não avaliar o grau de acometimento ósseo e de partes moles ao redor (Savoca, 1971).

Sabemos da importância do uso da cintilografia óssea como método complementar no diagnóstico das patologias ortopédicas, variando sua utilidade desde tumores, processos degenerativos articulares, pósoperatórios de artroplastias e fraturas por estresse (Etchebehere et al., 1998).

A cintilografia óssea surge como método eficiente no diagnóstico da patologia, com a literatura apontando alta sensibilidade e alterações em sua fase precoce (Prather et al., 1977).

Greaney et al. (1983) dividem as alterações cintilográficas em quatro níveis de forma subjetiva, na tentativa de quantificar o grau de acometimento ósseo.

A primeira classificação cintilográfica vem com o estudo de Chisin et al. (1987) que divide a patologia em quatro graus, sem correlação entre esta classificação e a evolução dos pacientes.

Zwas et al. (1987) apresentam classificação que correlaciona quatro níveis de acometimento ósseo ao tempo de recuperação do paciente, mas os estudos posteriores que tentam aplicar a classificação descrita para predizer o tempo de recuperação do paciente falham em demonstrar tal associação (Nielsen et al., 1991; Dutton et al., 2002). 
O aumento da captação na cintilografia óssea em indivíduos assintomáticos é bastante citada na literatura (Nielsen et al., 1991; Spitz e Newberg, 2002), e encontra explicação pela remodelação óssea, e conseqüente aumento metabólico, desde fases precoces até tardias da patologia.

Com o advento da ressonância magnética, os estudos passam a apresentar os achados que foram encontrados nos pacientes com fraturas de estresse quando submetidos ao novo método.

Lee e Yao (1988) descrevem os achados na ressonância magnética em cinco pacientes com diagnóstico clínico e confirmação cintilográfica de fraturas de estresse.

A literatura aponta a ressonância magnética com a mesma sensibilidade que a cintilografia óssea na avaliação da fratura de estresse, com a vantagem de avaliar melhor as partes moles ao redor do sítio de fratura (Ishibashi et al., 2002; Kiuru et al., 2003; Gaeta et al., 2005).

É de Fredericson et al. (1995) importante estudo que correlaciona a classificação cintilográfica proposta por Zwas et al. (1987) ao novo sistema de classificação por meio de ressonância magnética, relacionando também estes níveis com o prognóstico em termos de retorno do paciente à atividade esportiva.

Apesar das classificações existentes, não encontramos concordância na literatura em certas situações, como nas fases iniciais e mais avançadas da patologia. 
O tratamento da fratura de estresse é descrito na literatura como conservador, com poucas menções a respeito de métodos de aceleração do período de recuperação e abreviação do retorno do atleta ao esporte.

Em raras situações são citados tratamentos cirúrgicos, como no caso da fratura transversa do terço médio da tíbia, nas pseudoartroses ou nas fraturas de alto risco (Boden e Ashahr, 2001).

Whitelaw et al. (1989) descrevem a diminuição do tempo de recuperação de atletas com quadro de fraturas de estresse por uso de "brace" pneumático, fato comprovado por Swenson et al. (1997) em estudo randomizado com grupo controle.

O uso de órteses semi-rígidas ou macias encontra respaldo na literatura como fator de prevenção, em especial nos casos em que o paciente apresenta recidiva, pés planos ou com tendência à pronação excessiva (Finestone et al., 1999).

Não encontramos, na literatura, estudos que analisam outras formas de tratamento, usualmente preconizadas (fisioterapia, antiinflamatórios, palmilhas) em relação às fraturas de estresse.

Não restringimos a população com relação à idade, sexo ou raça para não limitarmos excessivamente a amostragem e por entendermos que estes fatores pudessem ser analisados como predisponentes.

O diagnóstico da patologia foi clínico, com confirmação por, pelo menos, um método de imagem (ressonância magnética ou cintilografia óssea). 
Mesmo entendendo que a fratura de estresse na tíbia possa ter formas distintas de apresentação, consideramos a patologia como única e todas as formas de apresentação foram incluídas neste estudo.

Apesar de não ser critério de exclusão, a fratura do córtex anterior da tíbia (segundo alguns autores apresenta evolução distinta com pior prognóstico), não houve nenhum caso desta fratura na casuística apresentada.

Realizamos avaliação clínica retrospectiva dos pacientes, para identificar fatores clínicos correlacionados à fratura por estresse.

Adotamos, para este estudo, a classificação de Fredericson et al. (1995) como base para a organização das imagens de ressonância magnética encontradas em nossos pacientes, por entendermos que se trata de metodologia já publicada na literatura, servindo de parâmetro para estabelecermos paralelo de comparação com nossa proposta de avaliação quantitativa.

A proposta de aplicação de contraste paramagnético no exame de ressonância magnética, objetivando a avaliação da perfusão e de seu clareamento, já foi descrita por Kiuru et al. (2001), porém não foi empregada no presente estudo. O contraste paramagnético, embora extremamente seguro, não é totalmente isento de efeitos colaterais. A justificativa de utilização de dois métodos de imagem encontra respaldo na literatura, uma vez que os dois métodos são estabelecidos e já reconhecidos como métodos complementares no diagnóstico das fraturas por estresse. A aplicação de contraste paramagnético na ressonância magnética foi 
abandonada pela dificuldade de aceitação por muitos pacientes, e por entendermos que a metodologia não encontra-se estabelecida na literatura para a avaliação dos casos de fraturas por estresse.

O critério de Zwas et al. (1987) para definição de fratura por estresse foi utilizado apenas para consideração da positividade da cintilografia óssea nos casos estudados na presente amostra, qual seja, consideramos positivos os casos em que houve alteração localizada e focal na cintilografia. Casos difusos e mal localizados foram considerados negativos, por compreendê-los como síndrome de estresse tibial anterior ou mesmo lesões relacionadas ao estresse antigas. Mesmo alterações focais discretas identificadas em $40 \%$ dos pacientes do grupo II poderiam representar alterações secundárias a estresse antigo ou em processo de consolidação residual; porém, pelos critérios de explicação do presente estudo, deveriam ser interpretados como sugestivos de fraturas. Deste fato entende-se a importância da associação dos achados de imagem com a clínica que o paciente apresenta. O que caracterizará melhor a especificidade diagnóstica com ambos os métodos é, de qualquer forma, a sintomatologia que o paciente apresenta no momento da investigação.

A avaliação quantitativa, metodologia já estabelecida e utilizada para avaliação de tumores ósseos (Citrin et al., 1974), ainda não havia sido aplicada na avaliação de fraturas por estresse. Não é de nosso conhecimento qualquer trabalho que já tenha investigado de forma retrospectiva ou prospectiva o emprego da avaliação semiquantitativa por técnica de região de interesse (ROI) nas fraturas por estresse. 
Não se identificaram estudos que relacionassem o índice de captação observado à cintilografia com sintomatologia, imagem ou tempo de recuperação de um paciente com fratura de estresse.

Empregou-se a metodologia de cintilografia com análise quantitativa já estabelecida em tumores ósseos e aplicamos nos pacientes com fraturas por estresse (Citrin et al., 1974).

Este tipo de avaliação foi proposto por entendermos que o grau de captação óssea, como indicador direto do grau de remodelação óssea do local acometido, pode ser estar relacionado a maior ou menor extensão e severidade da fratura.

A hipótese inicial de que um maior acometimento ósseo esteja relacionado com um tempo maior de recuperação foi testada, correlacionando o grau de acometimento ósseo (anatomicamente pela ressonância magnética e metabolicamente pela cintilografa óssea) ao tempo de recuperação.

Analisamos os resultados dos exames de imagem de duas maneiras: qualitativa e quantitativamente. Na avaliação qualitativa, consideramos apenas resultados positivos ou negativos, baseados em parâmetros já estabelecidos na literatura por Fredericson et al. (1995), para ressonância magnética, e Zwas et al. (1987), para cintilografia óssea.

Nesta etapa procuramos avaliar e comparar os métodos com relação à sensibilidade e especificidade.

Dentre os protocolos de reabilitação estudados na literatura, optamos pelo descrito por Arendt et al. (2003), que preconiza a reabilitação da fratura 
por estresse em quatro fases progressivas, pois o mesmo não define tempo pré-determinado para cada fase, ficando a critério da evolução clínica do paciente.

Por meio deste protocolo pudemos acompanhar individualmente a recuperação de cada paciente por, no mínimo, seis meses após o retorno à prática esportiva sem restrições (fase IV do protocolo).

Os pacientes foram orientados a retornar à corrida em esteira por encontrarmos descrição na literatura que esta modalidade de corrida apresenta menores riscos (Milgron et al., 2003).

Não utilizamos nenhum outro tratamento (suporte pneumático, palmilha, fisioterapia) que pudesse interferir na evolução, a não ser antiinflamatórios não hormonais por curta duração nos casos em que a sintomatologia dolorosa os fez necessário.

Não houve necessidade de imobilizar pacientes na fase inicial e, somente em dois casos, utilizaram-se muletas para retirada de carga por curto período e alívio da dor (previsto na fase I do protocolo).

A casuística do grupo I foi comparável com o grupo II (controle), por escolhermos, entre os voluntários, indivíduos praticantes de atividade física e com faixa etária semelhantes ao do grupo I.

Os grupos se mostraram comparáveis com relação à faixa etária, horas de treino semanal e atividade esportiva principal.

$\mathrm{Na}$ avaliação clínica dos resultados, encontramos a confirmação de que a patologia incide sobretudo na população fisicamente ativa, em 
especial nos esportes de impacto, sendo a corrida responsável pela maioria dos casos.

$\mathrm{Na}$ nossa amostra, 76,29\% praticavam a corrida como atividade principal (corredores ou triatletas), 9,52\% praticavam saltos como rotina na sua prática esportiva (basquetebol ou saltadores), e todos os pacientes buscavam melhor rendimento em atividades ritmadas, como encontramos descrição na literatura (Staniski et al., 1978).

Nosso grupo-controle foi escolhido dentre voluntários também praticantes de atividades de impacto, para que pudessem ser comparáveis ao grupo I sintomático, como podemos ver pela presença de 8 pacientes (80\%) corredores e 2 pacientes (20\%) triatletas.

Apesar de não constituir amostra significativa da população geral praticante de atividade física, mas de um grupo já sintomático, portanto, com hipótese diagnóstica de fratura de estresse, avaliamos a sensibilidade e especificidade como forma de comparação entre os métodos de imagem aplicados.

A alta sensibilidade apresentada por ambos os métodos pode estar relacionada ao fato de tratar-se de amostragem viciada da população, uma vez que estamos analisando praticantes de atividade física de alta intensidade com dor relacionada ao esforço, e suspeita clínica de fratura de estresse, portanto com diagnóstico altamente provável de fratura por estresse. 
A seleção de pacientes assim como os métodos e protocolos selecionados priorizam a sensibilidade com conseqüente prejuízo da especificidade.

Os achados de imagem em pacientes assintomáticos encontram respaldo na literatura e podem ser decorrentes de fatores inerentes à prática esportiva (Groshar et al., 1985; Matheson et al., 1987).

Os pacientes do grupo II (assintomático) são praticantes de atividade física regular e de impacto, com conseqüente alteração osteoperiostal na cintilografia óssea ou ressonância magnética, podendo estar em fase prévia de um quadro de fratura de estresse ou até mesmo em recuperação de fratura de estresse assintomática.

Encontramos distinção entre os grupos I e II com relação ao índice quantitativo obtido pela cintilografia óssea, o que nos permitiu chegar ao ponto crítico deste índice associado à probabilidade de uma fratura de estresse.

O ponto crítico encontrado (índice de 1,30) supõe uma probabilidade de $99 \%$ de fratura de estresse. Como mencionado anteriormente, este valor não encontra respaldo na literatura pela inexistência de trabalhos que investigam este tipo de técnica. Porém, analogicamente ao observado com o uso desta técnica em tumores, pode-se estimar o grau de agressividade do insulto pelo grau de remodelamento.

Este ponto crítico pode diminuir os achados de falsos-positivos ou negativos na cintilografia óssea, aumentando a sensibilidade e especificidade do método. Contudo, acreditamos que este ponto crítico 
possa ser de maior utilidade no seguimento e predição do tempo de repouso.

Na próxima etapa dividimos a casuística do grupo I em quatro subgrupos, correlacionando-a aos achados de imagem na ressonância pela classificação de Fredericson et al. (1995).

Por meio de análise de variância entre os subgrupos, foi possível a diferenciação em dois subgrupos, o que resultou em três níveis de intensidade de fratura de estresse:

- Ausente - até 1,3

- $\quad$ Moderado - entre 1,3 e 2,5

- Importante - acima de 2,5

Testamos a influência de diversos fatores no tempo de recuperação do paciente, e não encontramos relação do mesmo com idade, sexo, intensidade de treinamento, localização e intensidade da dor e tempo de início dos sintomas.

Quando avaliamos a correlação do índice de hipercaptação ao tempo de recuperação (afastando influência de outros fatores), encontramos correlação positiva entre o índice proposto e o tempo de recuperação do paciente $(R=0,63$ e $p<0,001)$.

A partir da curva de associação hipercaptação $X$ tempo de recuperação, montourse equação de regressão que associa as duas 
variáveis, permitindo-nos prever o tempo de recuperação pelo índice de hipercaptação encontrado na cintilografia óssea.

Os métodos analisados (cintilografia óssea e ressonância magnética) mostraram-se comparáveis na avaliação das fraturas por estresse, e ambos trazem informações interessantes, devendo ser associados, quando possível, para o melhor entendimento da patologia.

Existe correlação positiva entre o grau de acometimento ósseo e o tempo de recuperação, o que explica de certa forma o período de recuperação variável encontrado por nós na avaliação de alguns pacientes com fratura de estresse.

Correlacionou-se o índice de captação na cintilografia óssea ao tempo de recuperação dos pacientes, o que pode orientar o tempo de afastamento de atividades físicas, baseando-se nos achados cintilográficos. Contudo, são necessários estudos randomizados e controlados empregando a técnica do presente trabalho, com o objetivo de avaliar o uso da equação de regressão obtida em número maior de pacientes, de forma prospectiva e longitudinal.

A casuística deste estudo, conforme mencionado acima, pode ser considerada fator limitante para extração de maiores conclusões, e acreditase que, com maior número de pacientes possamos correlacionar mais precisamente o grau de acometimento ósseo ao tempo de retorno e alta, além de outros fatores de pior prognóstico relacionados com a patologia.

O tempo de seguimento de seis meses pode ser considerado curto; contudo, após esse período, os pacientes retornaram às suas atividades habituais, e outros fatores como alimentares, variações hormonais, 
intensidade de atividade física não foram controlados a partir deste prazo na amostra.

Não sabemos se este modelo poderia ser aplicado em outros locais com comportamento biomecânico distinto, mas ele fundamentaria novos estudos envolvendo outros locais freqüentes de fraturas por estresse (fêmur, fíbula, ossos dos pés).

Acreditamos que novos estudos devam se seguir, analisando a metodologia proposta em casos de fraturas por estresse em outros ossos, para avaliar os casos de recidiva com uma maior casuística, ajudando-nos a encontrar fatores que possam se correlacionar a pior prognóstico, retardo de consolidação ou pseudo-artrose. 


\section{CONCLUSÕES}

1. Os métodos de imagem analisados (cintilografia óssea e ressonância magnética) se mostram igualmente eficazes no diagnóstico da fratura de estresse de tíbia.

2. Existe correlação positiva entre o método de avaliação quantitativa na cintilografia óssea e a classificação de Fredericson et al (1995) na ressonância magnética.

3. Os resultados obtidos demonstram associação entre a intensidade de remodelação óssea observada à cintilografia óssea e o tempo de recuperação do paciente na casuística estudada. 
ANEXO 1

PROTOCOLO DE FRATURAS POR ESTRESSE

Nome:

Telefone:

e-mail: Idade: anos

Sexo: ( ) Masculino

( ) Feminino

Esporte:

Posição/categoria:

Treino: horas/semana $\mathrm{Km} /$ semana

Local da dor:

Início dos sintomas:

Característica da dor: ( ) em repouso

( ) atividades de vida diária

( ) em atividade física: ( ) somente no início

( ) ao final

( ) toda a atividade

( ) interrompe atividade

Alterações menstruais: ( ) amenorréia ( ) oligorréia

Exame Físico:

Peso:

$\mathrm{Kg}$ Altura: $\mathrm{cm}$

Pés: ( ) planos ( ) normais ( ) cavos

Geno: ( ) varo ( ) valgo ( ) bom alinhamento

Encurtamento: ( ) Quadríceps

( ) Cadeia posterior

( ) ambos

Comprimento

MID: $\mathrm{cm}$ MIE: $\mathrm{cm}$

Local da dor:

( ) edema

( ) dor à palpação

( ) calosidade 
RESSONÂNCIA MAGNÉTICA

(Clasificação de Fredericson)

\begin{tabular}{|l|l|}
\hline & \\
\hline 1 & $\begin{array}{l}\text { Edema periosteal leve a moderado em T2 } \\
\text { Medular normal em T1 e T2 }\end{array}$ \\
\hline 2 & $\begin{array}{l}\text { Edema periosteal moderado/intenso em T2 } \\
\text { Edema medular em T2, T1 normal }\end{array}$ \\
\hline 3 & $\begin{array}{l}\text { Edema periosteal intenso em T2 } \\
\text { Edema medular em T1 e T2 }\end{array}$ \\
\hline 4 & $\begin{array}{l}\text { Edema medular em T1 e T2 } \\
\text { Traço de fratura visível }\end{array}$ \\
\hline
\end{tabular}

Classificação segundo Fredericson:

CINTILOGRAFIA

(Classificação de Zwas)

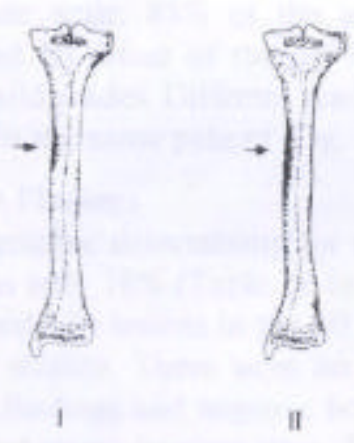

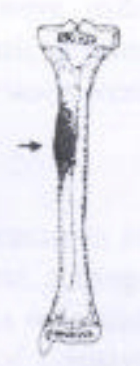

III

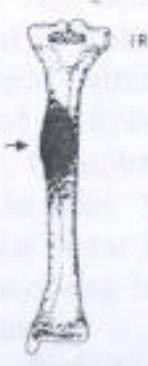

IV

Cortical Alongada Larga Transcortical Mal definida Bem definida Fusiforme Corticomedular

Classificação segundo Zwas:

HIPERCAPTAÇÃO RELATIVA:

TEMPO DE AFASTAMENTO: 
ANEXO 1

PROTOCOLO DE FRATURAS POR ESTRESSE

Nome:

Telefone:

e-mail: Idade: anos

Sexo: ( ) Masculino

( ) Feminino

Esporte:

Posição/categoria:

Treino: horas/semana $\mathrm{Km} /$ semana

Local da dor:

Início dos sintomas:

Característica da dor: ( ) em repouso

( ) atividades de vida diária

( ) em atividade física: ( ) somente no início

( ) ao final

( ) toda a atividade

( ) interrompe atividade

Alterações menstruais: ( ) amenorréia ( ) oligorréia

Exame Físico:

Peso:

$\mathrm{Kg}$ Altura: $\mathrm{cm}$

Pés: ( ) planos ( ) normais ( ) cavos

Geno: ( ) varo ( ) valgo ( ) bom alinhamento

Encurtamento: ( ) Quadríceps

( ) Cadeia posterior

( ) ambos

Comprimento

MID: $\mathrm{cm}$ MIE: $\mathrm{cm}$

Local da dor:

( ) edema

( ) dor à palpação

( ) calosidade 
RESSONÂNCIA MAGNÉTICA

(Clasificação de Fredericson)

\begin{tabular}{|l|l|}
\hline & \\
\hline 1 & $\begin{array}{l}\text { Edema periosteal leve a moderado em T2 } \\
\text { Medular normal em T1 e T2 }\end{array}$ \\
\hline 2 & $\begin{array}{l}\text { Edema periosteal moderado/intenso em T2 } \\
\text { Edema medular em T2, T1 normal }\end{array}$ \\
\hline 3 & $\begin{array}{l}\text { Edema periosteal intenso em T2 } \\
\text { Edema medular em T1 e T2 }\end{array}$ \\
\hline 4 & $\begin{array}{l}\text { Edema medular em T1 e T2 } \\
\text { Traço de fratura visível }\end{array}$ \\
\hline
\end{tabular}

Classificação segundo Fredericson:

CINTILOGRAFIA

(Classificação de Zwas)

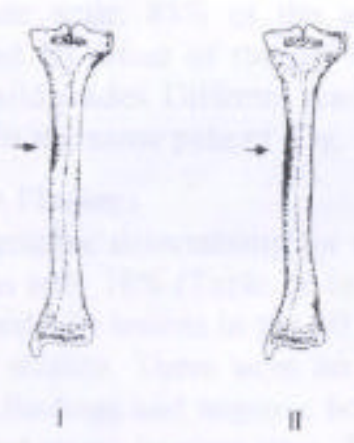

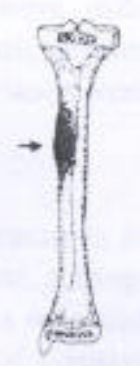

III

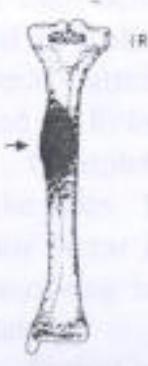

IV

Cortical Alongada Larga Transcortical Mal definida Bem definida Fusiforme Corticomedular

Classificação segundo Zwas:

HIPERCAPTAÇÃO RELATIVA:

TEMPO DE AFASTAMENTO: 


\section{REFERÊNCIAS}

Arendt E, Agel J, Heikes C, Griffiths H. Stress injuries to bone in college athletes: a retrospective review of experience at a single institution. Am J Sports Med. 2003; 31:959-68.

Ballas MT, Tytko J, Cookson D. Common overuse running injuries: diagnosis and management. Am Fam Physician. 1997; 55:2473-84.

Barrow GW, Saha S. Menstrual irregularity and stress fractures in collegiate female distance runners. Am J Sports Med. 1988; 16:209-16.

Bennell KL, Malcolm SA, Thomas SA, Reid SJ, Brukner PD, Ebeling PR, Wark JD. Risk factors for stress fractures in track and field athletes. A twelve-month prospective study. Am J Sports Med. 1996a; 24:810-8.

Bennell KL, Malcolm SA, Thomas SA, Wark JD, Brukner PD. The incidence and distribution of stress fractures in competitive track and field athletes. A twelve-month prospective study. Am J Sports Med. 1996b; 24:211-7.

Boden BP, Osbahr DC. High-risk stress fractures: evaluation and treatment. J Am Acad Orthop Surg. 2000; 8:344-353. 
Boden BP, Osbahr DC, Jimenez C. Low-risk stress fractures. Am J Sports Med. $2001 ; 29: 100-11$.

Burr DB, Milgrom C, Boyd RD, Higgins WL, Robin G, Radin EL. Experimental stress fractures of the tibia. Biological and mechanical aetiology in rabbits. J Bone Joint Surg Br. 1990; 72:370-5.

Burrows HJ. Fatigue infraction of the middle of the tibia in ballet dancers. J Bone Joint Surg Br. 1956; 38:83-94.

Chisin R, Milgrom C, Giladi M, Stein M, Margulies J, Kashtan H. Clinical significance of nonfocal scintigraphic findings in suspected tibial stress fractures. Clin Orthop Relat Res. 1987; 220:200-5.

Citrin DL, Bessent RG, Tuahy JB, Greig WR, Blumgart LH. Quantitative bone scanning: a method of bone response of bone metastases to treatment. The Lancet. 1974; 7867: 1132-3.

Crossley K, Bennell KL, Wrigley T, Oakes BW. Ground reaction forces, bone characteristics, and tibial stress fracture in male runners. Med Sci Sports Exerc. 1999; 31:1088-93.

Daffner RH, Martinez S, Gehweiler JA. Stress fractures in runners JAMA, 1982; 247: 1039-1041. 
Devas Mb. Longitudinal stress fractures. Another variety seen in long bones. J Bone Joint Surg Br. 1960; 42:508-14.

Devas Mb. Stress fractures of the tibia in athletes or shin soreness. J Bone Joint Surg Br. 1958; 40:227-39.

Dutton J, Bromhead SE, Speed CA, Menzies AR, Peters AM. Clinical value of grading the scintigraphic appearances of tibial stress fractures in military recruits. Clin Nucl Med. 2002; 27:18-21.

Etchebehere EC, Etchebehere M, Gamba R, Belangero W, Camargo EE. Orthopedic pathology of the lower extremities:scintigraphic evaluation in the thigh, knee and leg. Semin Nucl Med. 1998; 28:41-61.

Finestone A, Giladi M, Salmon EH, Mendelson S, Eldad A, Milgrom C. Prevention of stress fractures using custom biomechanical shoe orthoses. Clin Orthop Relat Res. 1999; 360:182-90.

Fredericson M, Bergman AG, Hoffman KL, Dillingham MS. Tibial stress reaction in runners. Correlation of clinical symptoms and scintigraphy with a new magnetic resonance imaging grading system. Am J Sports Med. $1995 ; 23: 472-81$. 
Gaeta M, Minutoli F, Scribano E, Ascenti G, Vinci S, Brischetta D, Magaudda L, Blandino A. CT and MR imaging findings in athletes with early tibial stress injuries:comparison with bone scintigraphy findings and emphasis on cortical abnormalities. Radiology. 2005; 235:553-561.

Giladi M, Milgrom C, Simkin A, Danon Y. Stress fractures. Identifiable risk factors. Am J Sports Med. 1991;19:647-52.

Greaney RB, Gerber FH, Laughlin RL, Kmet JP, Metz CD, Kilcheski TS, Rao BR, Silverman ED. Distribution and natural history of stress fractures in U.S. Marine recruits. Radiology. 1983;146:339-46.

Groshar D, Lam M, Even-Saphir E, Israel O, Front D. Stress fractures and bone pain: are they closely associated? Injury. 1985; 16:526-8.

Hartley JB. Fatigue fracture of the tibia. Brit Journ Surg. 1942; 30: 9-14.

Ishibashi Y, Okamura Y, Otsuka H, Nishizawa K, Sasaki T, Toh S. Comparison os scintigraphy and magnetic resonance imaging for stress injuries of bone. Clin J Sports Med. 2002; 12: 79-84.

Kiuru MJ, Pihlajamaki HK, Hietanen HJ, Ahovuo JA. MR imaging, bone scintigraphy, and radiography in bone stress injuries of the pelvis and the lower extremity. Acta Radiol. 2002; 43:207-12. 
Kiuru MJ, Pihlajamaki HK, Perkio JP, Ahovuo JA. Dynamic contrastenhanced MR imaging in symptomatic bone stress of the pelvis and he lower extremity. Acta Radiol. 2001; 42:277-85.

Korpelainen R, Orava S, Karpakka J, Siira P, Hulkko A. Risk factors for recurrent stress fractures in athletes. Am J Sports Med. 2001; 29:304-10.

Krivickas LS. Anatomical factors associated with overuse sports injuries. Sports Med. 1997; 24(2):132-46.

Lee JK, Yao L. Stress fractures: MR imaging. Radiology. 1988;169:21720.

Matheson GO, Clement DB, McKenzie DC, Taunton JE, Lloyd-Smith DR, Maclntyre JG. Stress fractures in athletes. A study of 320 cases. Am J Sports Med. 1987; 15:46-58.

Michael $\mathrm{RH}$, Holder LE. The soleus syndrome. A cause of medial tibial stress (shin splints). Am J Sports Med. 1985; 13:87-94.

Milgrom C, Finestone A, Segev S, Olin C, Arndt T, Ekenman I. Are overground or treadmill runners more likely to sustain tibial stress fracture? Br J Sports Med. 2003; 37:160-3. 
Monteleone GP Jr. Stress fractures in the athlete. Orthop Clin North Am. $1995 ; 26: 423-32$.

Mubarak SJ, Gould RN, Lee YF, Schmidt DA, Hargens AR. The medial tibial stress syndrome. Am J Sports Med. 1982; 10:201-5.

Nielsen MB, Hansen K, Holmer P, Dyrbye M. Tibial periosteal reactions in soldiers. A scintigraphic study of 29 cases of lower leg pain. Acta Orthop Scand. $1991 ; 62: 531-4$.

Orava S. Stress fractures. Br J Sports Med. 1980; 14:40-4.

Pozderac RV. Longitudinal tibial fatigue fracture: an uncommon stress fracture with characteristic features. Clin Nucl Med. 2002; 27:475-8.

Prather JL, Nusynowitz ML, Snowdy HA, Hughes AD, McCartney WH, Bagg RJ. Scintigraphic findings in stress fractures. J Bone Joint Surg Am. 1977; 59: 869-74.

Rettig AC, Shelbourne KD, McCarroll JR, Bisesi M, Watts J. The natural history and treatment of delayed union stress fractures of the anterior cortex of the tibia. Am J Sports Med. 1988; 16:250-5. 
Roub LW, Gumerman LW, Hanley EN, Clark MW, Goodman M, Herbert DL. Bone stress: a radionuclide imaging perspective. Radiology. 1979; 132: $431-8$.

Savoca CJ. Stress fractures. A classification of the earliest radiographic signs. Radiology. 1971; 100:519-24.

Scully TJ, Besterman G. Stress fracture--a preventable training injury. Mil Med. 1982; 147:285-7.

Shaffer RA, Rauh MJ, Brodine SK, Trone DW, Macera CA. Predictors os stress fractures susceptibility in young females recruits. Am J Sports Med. 2005 (in publish).

Shearman CM, Brandser EA, Parman LM, EHKhoury GY, Saltzman CL, Pyevich MT, Boles CA. Longitudinal tibial stress fractures: a report of eight cases and review of the literature. J Comput Assist Tomogr. 1998; 22: $265-9$.

Spitz DJ, Newberg AH. Imaging of stress fractures in the athlete. Radiol Clin N Am. 2002; 40:313-31.

Stanitski CL, McMaster JH, Scranton PE. On the nature of stress fractures. Am J Sports Med. 1978; 6:391-6. 
Swenson EJ Jr, DeHaven KE, Sebastianelli WJ, Hanks G, Kalenak A, Lynch JM. The effect of a pneumatic leg brace on return to play in athletes with tibial stress fractures. Am J Sports Med. 1997; 25:322-8.

Viitasalo JT, Kvist M. Some biomechanical aspects of the foot and ankle in athletes with and without shin splints. Am J Sports Med. 1983; 11:12530.

Whitelaw GP, Wetzler MJ, Levy AS, Segal D, Bissonnette K. A pneumatic leg brace for the treatment of tibial stress fractures. Clin Orthop Relat Res. $1991 ; 270: 301-5$.

Zwas ST, Elkanovitch R, Frank G. Interpretation and classification of bone scintigraphic findings in stress fractures. J Nucl Med. 1987; 28: 452-7. 
ANEXO 2 - Descrição da casuística do grupo I

\begin{tabular}{|c|c|c|c|c|c|c|c|c|c|c|c|}
\hline iniciais & $\begin{array}{l}\text { Idade } \\
\text { (anos) }\end{array}$ & Sexo & Lado & Esporte & $\begin{array}{c}\text { Treinamento } \\
\text { (horas/semana) }\end{array}$ & RM & $\begin{array}{c}\text { Classificação } \\
\text { de } \\
\text { Fredericson }\end{array}$ & $\begin{array}{c}\text { Cintilo- } \\
\text { grafia }\end{array}$ & $\begin{array}{c}\text { Hiper- } \\
\text { captação }\end{array}$ & Tempo & $\begin{array}{c}\text { Seguimento } \\
\text { (meses) }\end{array}$ \\
\hline $\mathrm{GHL}$ & 26 & $\mathrm{M}$ & $\overline{E S Q}$ & handebol & 7,0 & + & 1 & + & 1,600 & 4 & 12 \\
\hline GMC & 33 & $M$ & ESQ & corrida & 5,5 & + & 1 & + & 1,800 & 5 & 13 \\
\hline MSC & 38 & $\mathrm{~F}$ & $E S Q$ & corrida & 2,5 & + & 1 & + & 1,800 & 6 & 12 \\
\hline $\mathrm{RW}$ & 22 & $M$ & DIR & triatlo & 2,5 & + & 1 & + & 2,300 & 4 & 18 \\
\hline MTP & 26 & $\mathrm{~F}$ & DIR & corrida & 3,0 & + & 2 & + & 1,800 & 6 & 6 \\
\hline JES & 37 & $M$ & DIR & corrida & 5,0 & + & 2 & + & 1,900 & 5 & 9 \\
\hline $\mathrm{GZ}$ & 23 & $M$ & DIR & basquete & 5,0 & + & 2 & + & 1,900 & 5 & 7 \\
\hline CT & 23 & $\mathrm{~F}$ & DIR & corrida & 3,5 & + & 2 & + & 2,000 & 5 & 8 \\
\hline $\mathrm{CB}$ & 34 & $M$ & DIR & corrida & 4,0 & + & 2 & + & 2,100 & 6 & 10 \\
\hline SMB & 28 & $\mathrm{~F}$ & $E S Q$ & corrida & 5,0 & + & 2 & + & 2,200 & 6 & 12 \\
\hline $\mathrm{DM}$ & 27 & $M$ & ESQ & corrida & 3,0 & + & 2 & + & 2,300 & 4 & 15 \\
\hline JS & 28 & $\mathrm{~F}$ & DIR & saltos & 6,0 & + & 2 & + & 2,400 & 3 & 9 \\
\hline AM & 52 & $\mathrm{M}$ & ESQ & corrida & 3,0 & + & 2 & + & 2,600 & 8 & 24 \\
\hline $\mathrm{GL}$ & 25 & $\mathrm{M}$ & DIR & handebol & 7,0 & + & 3 & + & 2,100 & 6 & 22 \\
\hline $\mathrm{ACM}$ & 28 & $\mathrm{~F}$ & ESQ & corrida & 4,0 & + & 3 & + & 2,200 & 8 & 7 \\
\hline $\mathrm{MC}$ & 44 & $M$ & ESQ & corrida & 3,5 & + & 3 & + & 2,800 & 10 & 18 \\
\hline PAE & 26 & $M$ & DIR & corrida & 4,0 & + & 3 & + & 3,200 & 8 & 22 \\
\hline MLV & 26 & $F$ & $E S Q$ & Futebol & 3,5 & + & 3 & + & 3,500 & 7 & 12 \\
\hline $\mathrm{JO}$ & 36 & $\mathrm{M}$ & DIR & corrida & 3,5 & + & 3 & + & 3,900 & 6 & 21 \\
\hline SND & 26 & $M$ & $E S Q$ & triatlo & 3,5 & + & 4 & + & 4,300 & 16 & 15 \\
\hline SB & 56 & $\mathrm{~F}$ & DIR & corrida & 5,0 & + & 4 & + & 4,700 & 20 & 20 \\
\hline $\begin{array}{l}\text { Media } \\
\text { Desvio }\end{array}$ & 31,62 & & & & 4,24 & & & & 2,54 & 7,05 & 13,38 \\
\hline padrão & 9,39 & & & & 1,34 & & & & 0,88 & 4,04 & 6,26 \\
\hline Minimo & 22,00 & & & & 2,50 & & & & 1,60 & 3,00 & 6,00 \\
\hline Maximo & 56,00 & & & & 7,00 & & & & 4,70 & 20,00 & 24,00 \\
\hline
\end{tabular}


ANEXO 3 - Descrição da casuística do grupo II

\begin{tabular}{|c|c|c|c|c|c|c|c|c|c|}
\hline Iniciais & $\begin{array}{l}\text { Idade } \\
\text { (anos) }\end{array}$ & Sexo & Lado & Esporte & $\begin{array}{c}\text { Treinamento } \\
\text { (horas/semana) }\end{array}$ & RM & $\begin{array}{l}\text { Classificação de } \\
\text { Fredericson } \\
\end{array}$ & $\begin{array}{l}\text { Hiper- } \\
\text { Cintilo captação Tempo }\end{array}$ & $\begin{array}{c}\text { Seguimento } \\
\text { (meses) }\end{array}$ \\
\hline MAT & 29 & $\mathrm{M}$ & & corrida & 3,0 & - & 0 & $-\quad 1,120$ & \\
\hline WC & 39 & M & & corrida & 3,5 & - & 0 & 1,020 & \\
\hline $\mathrm{RI}$ & 26 & M & & corrida & 4,0 & - & 0 & 0,920 & \\
\hline LFT & 32 & M & & corrida & 3,5 & + & 1 & 1,130 & \\
\hline PM & 28 & $\mathrm{~F}$ & & corrida & 5,0 & - & 0 & 1,150 & \\
\hline ACC & 28 & $\mathrm{~F}$ & & triatlo & 2,5 & + & 1 & 1,180 & \\
\hline CDP & 26 & $\mathrm{~F}$ & & triatlo & 5,5 & + & 1 & 1,050 & \\
\hline KM & 27 & M & & corrida & 3,0 & - & 0 & 1,120 & \\
\hline FB & 32 & M & & corrida & 3,5 & + & 1 & 0,860 & \\
\hline HNM & 31 & M & & corrida & 5,5 & - & 0 & 0,970 & \\
\hline Media & 29,80 & & & & 3,90 & & & 1,05 & \\
\hline Desvio-Padrão & 3,94 & & & & 1,07 & & & 0,1072 & \\
\hline Minimo & 26,00 & & & & 2,50 & & & 0,86 & \\
\hline Maximo & 39,00 & & & & 5,50 & & & 1,18 & \\
\hline
\end{tabular}


Anexos 88

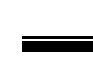

